Raj, A., Dwivedi, G., Sharma, A., Sousa Jabbour, A. B. L., \& Rajak, S. (2019). Barriers to the adoption of industry 4.0 technologies in the manufacturing sector: An inter-country comparative perspective. International Journal of Production Economics, 107546. https://doi.org/10.1016/j.ijpe.2019.107546 


\title{
Barriers to the Adoption of Industry 4.0 Technologies in the Manufacturing Sector: An Inter-Country Comparative Perspective
}

\author{
Alok Raj* \\ Production, Operations \& Decision Sciences \\ XLRI - Xavier School of Management \\ C. H. Area (East), Jamshedpur - 831001, India \\ Email: alokraj@xlri.ac.in

\begin{abstract}
Gourav Dwivedi
Department of Management Studies

Indian Institute of Technology Delhi

New Delhi-110016, India

Email: gourav.dwivedi@dms.iitd.ac.in
\end{abstract}

\begin{abstract}
Ankit Sharma
Operations Management Area

Indian Institute of Management Lucknow

Off Sitapur Road, Prabandh Nagar, Lucknow - 226013, India

Email: fpm17014@iiml.ac.in
\end{abstract}

Ana Beatriz Lopes de Sousa Jabbour

Montpellier Business School

Montpellier Research in Management

2300 Avenue des Moulins, 34000, Montpellier, France

Email: a.sousa-jabbour@montpellier-bs.com

\author{
Sonu Rajak \\ Department of Production Engineering, \\ Birla Institute of Technology \\ Mesra- 835215, Ranchi, India. \\ Email: sonu.production@gmail.com
}

* Corresponding Author. Tel.: +91 7054246541. 


\title{
Barriers to the Adoption of Industry 4.0 Technologies in the Manufacturing Sector: An Inter-Country Comparative Perspective
}

\begin{abstract}
This paper examines barriers to the implementation of Industry 4.0 technologies in the manufacturing sector in the context of both developed and developing economies. A comprehensive literature review, followed by discussions with industry experts, identifies 15 barriers, which are analyzed by means of a Grey Decision-Making Trial and Evaluation Laboratory (DEMATEL) approach. The 'lack of a digital strategy alongside resource scarcity' emerges as the most prominent barrier in both developed and developing economies. The influencing barriers identified suggest that improvements in standards and government regulation could facilitate the adoption of Industry 4.0 technologies in developing country case, whereas technological infrastructure is needed to promote the adoption of these technologies in developed country case. This study is one of the first to examine the implementation of Industry 4.0 in both developing and developed economies. This article highlights the difficulties in the diffusion of technological innovation resulting from a lack of coordinated national policies on Industry 4.0 in developing countries, which may prevent firms from fully experiencing the Industry 4.0 revolution. The results of this study may help decision makers and practitioners to address the barriers highlighted, paving the way for successful implementation of Industry 4.0 across the manufacturing sector.
\end{abstract}

Keywords: Industry 4.0; Barriers; Grey-DEMATEL; developed economy; developing economy 


\section{Introduction}

Industry 4.0, also termed the fourth Industrial revolution, is currently a burgeoning research topic (Chiarello et al., 2018). It can be seen as the convergence of several emerging concepts and new technologies, such as radio-frequency identification (RFID), big data, cloud computing, smart sensors, machine learning (ML), robotics, additive manufacturing (AM), artificial intelligence (AI), augmented reality and the Internet of Things (IoT) (Li, 2017; Schwab, 2017). The advanced technologies involved in Industry 4.0 are restructuring entire production systems by transforming analog and centralized workflows into digital and decentralized production processes. Industry 4.0 integrates people, machines, and data, creating more agile and responsive supply chains.

Despite the benefits that the adoption of Industry 4.0 technologies brings to supply chains, there is a long way to go (Dalenogare et al., 2019; Frank, et al., 2019). 2018). For instance, the results of a recent survey conducted by the consulting firm Deloitte in 19 countries reveals that only $14 \%$ of chief executive officers are confident that their organizations are fully prepared to incorporate the changes brought about by Industry $4.0^{1}$.

There is previous scientific research on barriers to the adoption of Industry 4.0 technologies. Some of the research previously conducted is based on empirical data by means of survey research (e.g. Turkes et al., 2019; Stentoft et al., 2019) and interview case studies (e.g. Horváth and Szabó, 2019; Machado et al., 2019). Further research focusing on mathematical techniques has also analyzed barriers to Industry 4.0 (e.g. Saatçioğlu et al., 2019; Aggarwal et al., 2019; Karadayi-Usta, 2019; Kamble et al., 2018). The scientific debate on this topic is still in progress, and more research is needed before a general consensus can be reached. Different research methods have been applied to this topic across different countries (e.g. India, Turkey, Romania, Demark, Sweden, and Hungary). Therefore, this article aims to examine the barriers to the implementation of Industry 4.0 technologies in the manufacturing sector in the context of both developed and developing economies, based on a Grey Decision-Making Trial and Evaluation Laboratory (DEMATEL) approach.

The research questions considered in this paper are as follows:

RQ1: What are the barriers to the implementation of Industry 4.0 in the manufacturing industries of developed and developing countries?

RQ2: What are the causalities and dependencies between these barriers?

RQ3: What are the hierarchical levels among these barriers? 
RQ4: What are the differences between the barriers to Industry 4.0 in developing and developed countries?

Grey-DEMATEL is a technique that identifies the total degree of influence of each barrier on other barriers, resulting in a better decoding of the uncertainty and vagueness contained in responses from experts (Si et al., 2018). Thus, this technique provides improved analysis compared with the application of interpretive structural modeling (ISM), for instance.

The policies created by developed and developing countries to enable the advancement of the Industry 4.0 digital revolution are different. Developed countries have generally formulated national strategies for development, whereas developing countries have adopted Industry 4.0 technologies on a corporate level, depending on individual corporate initiatives rather than national and coordinated policies (Bogoviz et al., 2019). Barriers to the diffusion and adoption of new technology are often present (Parente and Prescott, 1994). Therefore, it is important to investigate the different barriers that hinder the adoption of Industry 4.0 in developed as well as emerging economies. Studies examining this difference are vital, as companies operating across a variety of countries with differing economic conditions want to implement Industry 4.0 technologies across the board.

The barriers studied in this article were identified based on a comprehensive literature review and discussion with industry experts. The causal relationships between barriers were established using a Grey-DEMATEL approach. This approach was applied in an Indian company, representing a developing economy, as well as a French company, representing a developed economy. This study makes manifold contributions to the literature on this topic by identifying and analyzing these barriers in the context of developed as well as emerging economies, an understanding which is necessary to the smooth adoption of Industry 4.0. This analysis, based on the Grey-DEMATEL approach, provides useful insights and actionable points for manufacturing companies.

The rest of this paper is organized as follows: Section 2 presents and discusses Industry 4.0 literature and the barriers to implementing Industry 4.0 technologies. The research methodology is presented in Section 3. Real case application is demonstrated in Section 4. The key findings are discussed in Section 5. Finally, the conclusions and suggestions for future research are outlined in Section 6. 


\section{Literature Review}

This section gives an overview of the existing literature on Industry 4.0, following which the barriers inhibiting the adoption of Industry 4.0 in manufacturing sector are discussed. In the last part of this section the analytical approach is outlined.

\subsection{Industry 4.0}

The term "Industry 4.0" was first coined at the Hanover Fair in 2011. Subsequently, in 2013, the German government adopted it as a strategic initiative to revolutionize the manufacturing industry (Li, 2017; Xu et al., 2018). Recently, Industry 4.0 has gained increasing attention due to its numerous benefits to manufacturing organizations (Dalenogare et al., 2018). However, academic research on Industry 4.0 is still in the nascent stage (Horváth and Szabó, 2019).

A number of authors have recently conducted literature reviews exploring future research avenues in this area (Lu, 2017; Xu et al., 2018; Hofmann and Rüsch 2017). Hofmann and Rüsch (2017) discuss the opportunities of Industry 4.0 in the context of logistics. They argue that management is facing challenges to the implementation of Industry 4.0 because companies may not observe any short-term financial returns after implementation of Industry 4.0. Along similar lines, in the context of logistics, Barreto et al. (2017) analyze the requirements that may enable firms to be more efficient at implementing Industry 4.0. Haddud et al. (2017) and Ben-Daya et al. (2017) extend the concept of Industry 4.0 from logistics to supply chains. Haddud et al. (2017) analyze potential benefits and challenges associated with the integration of Industry 4.0 into supply chains, while Ben-Daya et al. (2017) explore the role of the IoT and its impact on supply chain management performance. It is necessary to integrate several technologies simultaneously across the supply chain for the implementation of Industry 4.0. Oesterreich and Teuteberg (2016) investigate the challenges that Industry 4.0 presents for the construction industry. Fettermann et al. (2018) examine the requirements of different technologies, such as radio frequency identifiers, sensors, processing in the cloud and cyber-physical systems. Meanwhile, Li et al. (2017) discuss the technological drivers of Industry 4.0 across the supply chain. Dalenogare et al. (2018) analyze the impact of Industry 4.0 technologies on industrial performance in a Brazilian context.

In a number of interesting studies, authors have tried to link two different emerging concepts related to operations management, such as lean manufacturing and Industry 4.0, and the circular economy and Industry 4.0. Mrugalska and Wyrwicka (2017) look at how the concepts of 
lean manufacturing and Industry 4.0 can coexist and support each other. Lopes de Sousa Jabbour et al. (2018) propose that different Industry 4.0 technologies could assist the implementation of circular economy strategies. The authors reveal that there is a mutually beneficial relationship between Industry 4.0 and the circular economy. Ivanov et al. (2018) analyze the relationship between big data analytics, additive manufacturing, advanced trace \& tracking systems, Industry 4.0 and supply chain disruption risks, as well as how digitalization can contribute to enhancing ripple effect control. Li (2017) compares Germany's "Industry 4.0" and China's "Made-in-China 2025" and has evaluated the position taken by China in "Made-in-China 2025." The authors argue that firms across China are facing several barriers due to various issues. However, these barriers to implementing Industry 4.0 in the manufacturing industry have not yet been investigated (Moktadir et al., 2018). The next subsection will discuss these barriers.

\subsection{Barriers to the Adoption of Industry 4.0}

The majority of researchers agree that the investigation of barriers related to implementation of Industry 4.0 remains largely unexplored in the extant literature and merits further investigation (de Sousa Jabbour et al., 2018a, b; Kamble et al., 2018; Horváth and Szabó, 2019; Oesterreich and Teuteberg, 2016; Xu et al., 2018).

There has been some fragmented analysis of these barriers (Horváth and Szabó, 2019); for instance, certain authors suggest that the lack of a skilled workforce, conflicts between workers due to changing working environments (Kiel et al., 2017; Müller and Voigt, 2017), shortage of financial resources (Kiel et al., 2017; PwC, 2014), data security (Kiel et al., 2017; McKinsey, 2016), low degrees of standardization, poor understanding of integration (Müller and Voigt, 2016) and systems architecture $(\mathrm{PwC}, 2014)$ are the major obstacles to the implementation of Industry 4.0. However, to date these barriers have only been analyzed individually, and generally from a technological perspective. The adoption of Industry 4.0 is a complex process, within which factors influence each other (Horváth and Szabó, 2019); therefore, a comprehensive consideration of all these factors is needed.

Much of the research on barriers to the adoption of Industry 4.0 technologies has been conducted based on empirical data by means of survey research (e.g. Turkes et al., 2019; Stentoft et al., 2019) and interview case studies (e.g. Horváth and Szabó, 2019; Machado et al., 2019). These studies highlight those barriers which prevent companies located in developed and 
developing countries (e.g. Romania, Denmark, Hungary, and Sweden) from achieving digital readiness. The extant findings state that a 'lack of knowledge about Industry 4.0', 'more focus on the costs of developing the company' and 'lack of understanding of the strategic importance of Industry $4.0^{\prime}$ are the most prominent barriers faced by small and medium sized companies in Romania to adopting Industry 4.0 technologies (Turkes et al., 2019). The maturity level of a company's digital transformation influences managers' perception of barriers to Industry 4.0 according to Machado et al., 2019, and organizational resistance from employees and middle management levels are likely to hinder the adoption of Industry 4.0 technologies within small and medium sized companies in Hungary (Horváth and Szabó, 2019).

Other researchers have focused on using mathematical techniques to analyze the barriers to Industry 4.0 (e.g. Saatçioğlu et al., 2019; Aggarwal et al., 2019; Karadayi-Usta, 2019; Kamble et al., 2018). Kamble et al. (2018) analyze the relationships between 12 barriers to Industry 4.0 adoption in the context of Indian manufacturing companies by means of interpretive structural modeling (ISM) and fuzzy MICMAC (Matriced' Impacts Croise's Multiplication Appliquée a UN Classement). Their main finding is that 'legal and contractual uncertainty' is the barrier that most influences the others. Karadayi-Usta (2019) also applies ISM and MICMAC to related barriers in the firm Bosch, and investigates the ways in which the barriers affect each other. 'Lack of education system' is identified as the main barrier in this study. Aggarwal et al. (2019) analyze six barriers to Industry 4.0 in India using the DEMATEL approach and show that 'management commitment' was both the most prominent and influential barrier. Finally, Saatçioğlu et al. (2019) identify, by means of ISM, that 'lack of vision' was the most prominent barrier affecting other barriers studied in the context of Turkish companies.

Horváth and Szabó (2019) and Kamble et al. (2018) suggest that the adoption of Industry 4.0 in the context of developing versus developed economies needs further investigation. Horváth and Szabó (2019) propose to analyze Industry 4.0 through a geographical lens, in order to compare similarities and differences across regions. Comparative geographical studies are vital in today's economic environment, as the companies implementing Industry 4.0 often have a presence in multiple countries. These companies need to implement these technologies in all major markets to in order to exploit their potential benefits. Therefore, an analysis of the barriers in different geographical areas is crucial if we are to fully maximize the benefits of Industry 4.0. 


\subsection{Evaluating the Relationships Between Barriers}

This section describes the approaches utilized to analyze the barriers identified. As presented in Table 1, most studies in the context of Industry 4.0 are based on conceptual discussion and literature reviews. Furthermore, they tend to be based on magazine articles and conference papers, since very few papers have been published in high impact scientific journals. Authors have investigated the relationships between barriers in different contexts using a number of different approaches, which are outlined below.

Three different Multi-criteria decision-making (MCDM) techniques - AHP, ISM and DEMATEL - are widely applied to analyze and establish relationships between barriers (Mangla et al., 2018). However, only two of the papers analyzed in this study used an MCDM approach to establish the contextual relationship between the identified barriers to Industry 4.0 adoption (Karadayi-Usta, 2019; Kamble et al., 2018). Furthermore, causality and relationships between barriers has been identified as a future avenue of research.

DEMATEL is one method that establishes contextual as well as causal relationships (Gabus and Fontela, 1972). DEMATEL has several advantages over Analytical Hierarchical Process (AHP) and interpretive structural modeling (ISM). When using the AHP method, one assumes that the criteria are independent of each other, which tends not to be realistic in practical scenarios. ISM is another popular method which establishes relationships between variables. However, while ISM establishes these relationships based on their dependency and driving power, it does not indicate the severity of their effects. DEMATEL is effective when using a small sample composed of experts (Lee et al., 2013). For instance, Bai and Sarkis, 2013 apply DEMATEL in the case of a sample of three experts. Therefore, DEMATEL has an advantage over other MCDM methods because it reveals the relationships between the criteria and prioritizes them based on the nature of these relationships, as well as the severity of their effects on each other. This method deals with complex causal relationships among the variables by using a combination of matrices and graphs.

Some studies combine DEMATEL with the Grey approach (Bai and Sarkis, 2013; Xia et al., 2015) and argue that this method is more effective than DEMATEL alone. Deng (1982) first introduced Grey Theory. In real-life scenarios, capturing precise information (Fu et al., 2001; Li et al., 2007) from imprecise human responses and interactions presents a huge challenge. Attempting to capture this information inevitably leads to biases and vague results. Grey Theory 
accounts for inappropriate or inaccurate human judgments and can be successfully incorporated into any decision-making process to improve the accuracy of judgments (Tseng, 2009). In the literature, authors also use the fuzzy concept to account for the vagueness of human decisionmaking. However, the Grey technique has an advantage over the fuzzy concept; the fuzzy concept struggles to accurately map membership functions that are triangular or trapezoidal, whereas these are easily handled using the Grey concept (Xia et al., 2015). Therefore Grey-DEMATEL has emerged as an effective approach to establishing the relationships between different barriers.

From the above discussion it is evident that studies on the barriers to Industry $4.0 \mathrm{often}$ focus on only one factor. Based on the literature review and to the best of the authors' knowledge, there are, as yet, no studies comparing the causality and dependencies of Industry 4.0 implementation barriers across different economic contexts. This study bridges the research gap by identifying a set of barriers and evaluating their relationships in the context of developed and developing economies using the proposed MCDM technique (Grey - DEMATEL).

\section{$<$ Insert Table 1 here $>$}

\section{Research Methodology}

The proposed methodology comprises four stages in order to analyze barriers to the implementation of Industry 4.0 across different economic contexts. In the first stage, barriers to the successful implementation of Industry 4.0 in the manufacturing sector were identified based on the literature review and experts' input. In the second stage, relationships between these barriers were analyzed from the perspectives of six industry experts with the assistance of the GreyDEMATEL technique. A matrix comprising a list of the identified barriers was provided to six manufacturing experts to fill in. From their responses, an initial direct relationship matrix was formed and, subsequently, the sequential processes of Grey-DEMATEL were followed to evaluate the causal barriers to Industry 4.0. The results obtained were validated by feedback from experts. In the end, sensitivity analysis was carried out to check the robustness of the analysis. Figure 1 shows the proposed framework for identifying barriers to the implementation of Industry 4.0.

\section{$<$ Insert Figure 1 here $>$}


Stage 1. Selection of barriers and their meanings

Barriers were identified using three steps, based on a review of the relevant literature and input from experts. In the first step, we searched for research articles published in scientific journals in the leading databases (Scopus and Web of Science), using the keywords 'Industry 4.0' and 'barriers'. The initial searches identified 130 titles, with some degree of overlap (50 from Scopus and 80 from Web of Science). After eliminating duplicates and irrelevant articles, approximately 50 papers were ultimately selected for the literature review. In the second step, having completed a review of these articles, we identified 23 different barriers. In the third step, a group of experts was selected and provided with the final list of barriers. This group consisted of recognized industry experts, identified based on purposive sampling. Initially, we contacted twelve experts, six of whom (four from India and two from France) agreed to participate in the study and discussion. All the experts consulted have comprehensive knowledge in the field of Industry 4.0, and have worked in the industry for over five years. A Skype call was arranged for the discussion. The 23 barriers identified in the second step were presented to the six experts for discussion, and the experts were free to edit the list of barriers. Based on these discussions and feedback from the group of experts, 15 different barriers were found relevant to implementing Industry 4.0 in the manufacturing industry.

\subsection{High Investment in Industry 4.0 Implementation}

According to Geissbauer et al. (2014), firms intent on implementing Industry 4.0 initiatives would have to commit to increasing their planned yearly capital investments by $50 \%$ for the next five years. This not only implies that firms must re-engineer their existing strategies, but also that a considerable amount of investment is needed to achieve Industry 4.0 goals. Furthermore, Kache and Seuring (2017) support this assertion by mentioning that high investment regarding people, processes and technology is required both at the corporate level and the supply chain level. Breunig et al. (2016) state that most firms are still reluctant to invest in Industry 4.0 related R\&D, which poses challengingly high investment requirements. Along similar lines, Dalenogare et al. (2018) indicate that Brazilian enterprises also expect higher investment in digital technologies.

\subsection{Lack of Clarity Regarding Economic Benefit}


The productivity gains and economic benefits of spending on information technology have always been questioned (Brynjolfsson, 1993; Osterman 1986; Stolarick 1999). The productivity paradox regarding technology implementation thus brings uncertainty about the clear assessment of the economic benefits of investment in technology.

\subsection{Challenges in Value-chain Integration}

Breunig et al. (2016) discuss the challenge of breaking down obstacles between various organizational departments in order to achieve the smooth coordination needed for Industry 4.0. This kind of challenge is amplified when multiple organizations in the value chain require integration. Geissbauer et al. (2014) highlight the need for close cooperation among value-chain partners along with horizontal value-chain integration. Furthermore, Majeed and Rupasinghe (2017) state that most firms fail due to poor integration of the IoT in an Industry 4.0 environment. This argument is further supported by Dalenogare et al. (2018).

\subsection{Risk of Security Breaches}

Increased connectivity - i.e. complex links among value-chain partners - creates unanimous concerns about the security risks of sharing information among channel partners (Geissbauer et al., 2014). Breunig et al. (2016) talk not only about firms' cyber-security concerns but also about the fear of losing their data to third-party software and service providers in Industry 4.0. Lee and Lee (2015) discuss this risk as one of the potential challenges in IoT implementation, as hackers would pose serious threats.

\subsection{Low Maturity Level of Preferred Technology}

Lee and Lee (2015) further raise the issue of potential chaos when early stage, poorly tested technologies are deployed. Such technologies may not possess stability regarding standards,

privacy issues and data security, and the increasing number of partially tested devices can result in chaos. The paper further argues that while this doesn't pose a significant problem in an unconnected world, it could critically affect an interconnected system of technologies.

\subsection{Inequality}


Industry 4.0 will bring about social tension in the labor market. The effect of this could be positive or negative, but technology will segregate the market into low skills/low pay and high skills/high pay categories, resulting in social tension (Schwab, 2017). It is further argued that Industry 4.0 will benefit the owners of intellectual capital and their shareholders, while also deepening the gap between those dependent on labor versus those dependent on capital, increasing inequality.

\subsection{Disruption to Existing Jobs}

Haddud et al. (2017) discuss the challenges presented by Industry 4.0 and raise the issue of disruption to existing jobs. Although they do not perceive displacement of human resources as a potential challenge, O'Halloran and Kvochko (2015), along with Ryan and Watson (2017), perceive displacement of humans as a potential challenge in a social and organizational context. Schwab (2017) argues that the advancements in Industry 4.0 would increase inequality, potentially disrupting the labor market.

\subsection{Lack of Standards, Regulations and Forms of Certification}

Schröder (2016) talks about reservations among small and medium enterprises (SMEs) regarding the adoption of Industry 4.0 due to the lack of common standards and regulations. The author further points out that this lack of standards challenges SMEs when joining value-creation activities and networks. Furthermore, advancing technology is continually challenging regulators and legislators. They face difficulties in safeguarding the interests of customers when they are not adapted to rapidly changing technology and its broad impact. Thus, regulators must adapt quickly to changing technological innovations in order to understand what they are regulating (Schwab, 2017).

\subsection{Lack of Infrastructure}

Wide-ranging broadband infrastructure is a must in realizing Industry 4.0. One of the major pitfalls, even in developed nations such as Germany, is a lack of reliable high-speed broadband for SMEs. Only big players with vast resources currently have this kind of technology at their disposal (Schröder, 2016). Industry 4.0 would require every channel member to be integrated; thus, digital infrastructure is a factor that cannot be ignored. Buntz (2016) cites the results of Penton's survey, 
wherein $33 \%$ of respondents believed that lack of infrastructure is an issue in adopting IoT. The survey further found that many firms are now collaborating instead of competing regarding the necessary infrastructure development needed for Industry 4.0.

\subsection{Lack of Digital Skills}

Among the non-technical challenges that the IoT (and therefore Industry 4.0) faces, employees with the required knowledge and skills remain key (Hung, 2016). Breunig et al. (2016) also argue that many firms admit that they do not have the necessary expertise or skills to realize the full potential of Industry 4.0 applications. Breunig further states that a lack of digital skills and expertise paralyzes firms' ability to collaborate with their software solution providers when their workforces lack the expertise to use what they are buying. Geissbauer et al. (2014) suggest that under-qualified employees are the second major barrier to realizing Industry 4.0, as businesses will become more data-driven and agile, requiring a more qualified workforce.

\subsection{Challenges in Ensuring Data Quality}

Quality of data has four aspects: consistency, completeness, accuracy and redundancy (Chen et al., 2014). In the age of fully realized big data, in which firms would have to be interconnected, a large amount of data would be generated, and the complex nature of such data, along with its heterogeneity, makes it difficult to measure completeness and data accuracy. This increases the risk of false discoveries (Lohr, 2012). Furthermore, when data frequently changes and is shared with multiple collaborators, data integrity and consistency becomes a major challenge (Khan et al., 2014). This would be the case in Industry 4.0, as firms will be interconnected at a much higher level than previously.

\subsection{Lack of Internal Digital Culture and Training}

To harness the value of Industry 4.0, it becomes necessary to have strong internal capabilities in the team and a culture that fosters innovation and is open to experimentation (Breunig et al., 2016). Furthermore, it is argued that employees with these capabilities would be in higher demand and much lower supply in such a scenario. Thus, firms would need to be ready to shift to where such employees were available. Such resources would inculcate an internal digital 
culture and make it possible to integrate a team with experts from different domains (Breunig et al., 2016).

\subsection{Resistance to Change}

One of the barriers to the implementation of IoT in organizations relates to employees who are unwilling to change the way they work. These employees resist using new technologies and the practices associated with them (Haddud et al., 2017). Another dimension of resistance is presented by Lee and Lee (2015), who argue that some IoT technologies generate an enormous amount of personal data, such as household, health-related and financial behavior-related data, which many enterprises could use to leverage their businesses. This deters firms, as well as individuals, from adopting IoT for fear of privacy breaches.

\subsection{Ineffective Change Management}

Over the last decade, technology has immensely altered the way change happens. Once, change was considered transactional and thus easy to manage; now it has become radical, openended, continuous and complex. In other words, it has become transformational and thus very difficult to carry out successfully (Anderson and Anderson, 2010). Under Industry 4.0, increasingly open-ended systems would be more complex than ever, and effective change management would be a key challenge for organizations.

\subsection{Lack of a Digital Strategy Alongside Resource Scarcity}

Industry 4.0 requires a consistent availability and flow of data both horizontally and vertically, in and across organizations (Schröder, 2016). In this context, SMEs face major challenges, as they face resource constraints, unlike their larger counterparts. Ahlers (2015) talks about the Innovation Readiness Index (IRI), developed by Pierre Audoin Consultants (PAC) in Germany, and states that the majority of medium-sized firms reject the use of cloud computing. Schröder (2016) indicates that this issue arises from the senior management of firms, as they are more cautious about adopting Industry 4.0 technologies. Furthermore, Ahlers (2015) argues that the implementation of Industry 4.0 is a strategic decision, and that reservations at the top management level make it potentially difficult to develop a digital strategy to implement Industry 4.0 initiatives. 
All the barriers discussed above are summarized in Table 2.

\section{$<$ Insert Table 2 here $>$}

Stage 2. The Grey-DEMATEL approach

The DEMATEL method was applied in order to identify the relationships between barriers. The complexity of these relationships make this a particularly daunting task, especially as they exist in such large in numbers. It is, therefore, imperative to use multi-criteria decision-making (MCDM) techniques to consider the various trade-offs and contradictory objectives related to these relationships. DEMATEL is an advanced MCDM technique that analyzes inter-dependent relationships and identifies influential effects at work between significant factors (Gabus and Fontela, 1972). For this reason, Grey-DEMATEL was our favored approach.

The Grey-DEMATEL procedure is explained in the following steps (adopted from Bai and Sarkis, 2013; Rajesh and Ravi, 2015):

Step 1: Computation of the initial relation matrices

Let $n$ represent the number of identified barriers to the implementation of Industry 4.0 in the manufacturing sector, and let $k$ represent the number of decision makers. Each respondent, $k$, was asked to evaluate the direct influence of factor $i$ over factor $j$, on an integer scale of $n$ barriers: where a score of 0 signifies no influence, 1 - very low influence, 2 - low influence, 3 - medium influence, 4 - high influence and 5 indicates a very high influence. Thus, we get $k$ initial relation matrices.

Step 2: Computation of the grey-relation matrix

The integer scale results must now be modified to fit the respective grey values with higher and lower limit values (Deng, 1989), as shown below:

$$
\otimes \tilde{x}_{i j}^{k}=\left(\underline{\otimes} \tilde{x}_{i j}^{k}, \bar{\otimes} \tilde{x}_{i j}^{k}\right)
$$

where $1 \leq k \leq K ; 1 \leq i \leq n ; 1 \leq j \leq n$, and $\underline{\otimes} \tilde{x}_{i j}^{k}$ represents the lower limit of grey values whereas $\bar{\otimes} \tilde{x}_{i j}^{k}$ represents the upper limit of grey values for respondent $k$ in terms of the relationship valuation between factor $i$ and factor $j$. 
Step 3: Computation of the average grey-relation matrix $(A)$

$A$, the average grey-relation matrix $\left[\otimes x_{i j}^{k}\right]$, can be obtained from the $K$ grey-relation matrices (Rajesh \& Ravi, 2015; Kose et al., 2013), as shown below:

$$
\begin{aligned}
& \otimes x_{i j}^{k}=\left(\frac{\sum_{k} \frac{\otimes}{x_{i j}^{k}}}{K}, \frac{\sum_{k} \bar{\otimes} \tilde{x}_{i j}^{k}}{K}\right) \\
& A=\left[\otimes x_{i j}^{k}\right]
\end{aligned}
$$

Step 4: Determination of the crisp-relation matrix $(Z)$

The crisp values of the grey number, $\otimes x_{i j}^{k}=\left(\underline{\otimes} x_{i j}^{k}, \bar{\otimes} x_{i j}^{k}\right)$, can be obtained by using a modified version of the CFCS method (Xia et al., 2015; Rajesh \& Ravi, 2015), as shown in the next three steps:

(i) Normalization

$$
\begin{aligned}
& \underline{\otimes} \bar{x}_{i j}^{k}=\left(\underline{\otimes} x_{i j}^{k}-\min _{j} \underline{\otimes} x_{i j}^{k}\right) / \Delta_{\min }^{\max } \\
& \bar{\otimes} \bar{x}_{i j}^{k}=\left(\bar{\otimes} x_{i j}^{k}-\min _{j} \bar{\otimes} x_{i j}^{k}\right) / \Delta_{\min }^{\max }
\end{aligned}
$$

where

$$
\Delta_{\min }^{\max }=\max _{j} \bar{\otimes} x_{i j}^{k}-\min _{j} \underline{\otimes} x_{i j}^{k}
$$

(ii) Computation of a total normalized crisp value

$$
Y_{i j}^{k}=\left(\frac{\underline{\otimes} \bar{x}_{i j}^{k}\left(1-\underline{\otimes} \bar{x}_{i j}^{k}\right)+\left(\bar{\otimes} \bar{x}_{i j}^{k} \times \bar{\otimes} \bar{x}_{i j}^{k}\right)}{\left(1-\underline{\otimes} \bar{x}_{i j}^{k}+\bar{\otimes} \bar{x}_{i j}^{k}\right)}\right)
$$

(iii) Determination of final crisp values

$$
z_{i j}^{k}=\left(\min _{j} \underline{\otimes} x_{i j}^{k}+\left(Y_{i j}^{k} \times \Delta_{\min }^{\max }\right)\right)
$$

and

$$
Z=\left[z_{i j}^{k}\right]
$$

Step 5: Computation of the normalized direct crisp-relation matrix $(X)$

The normalized direct crisp-relation matrix $(X)$ can be determined from the following equations. Each element in this matrix lies between 0 and 1. 
$\mathrm{S}=\frac{1}{\max _{1 \leq \mathrm{i} \leq \mathrm{n}} \sum_{\mathrm{j}=1}^{\mathrm{n}} z_{i j}}$

and

$\mathrm{X}=\mathrm{S} \times \mathrm{Z}$

where $S$ is a normalization factor and $Z$ is a crisp-relation matrix.

Step 6: Computation of the total-relation matrix $(T)$

The total-relation matrix $(T)$ can be obtained from the following equation:

$$
\mathrm{T}=\mathrm{X} \times(\mathrm{I}-\mathrm{X})^{-1}
$$

where $I$ represents the identity matrix.

Step 7: Obtaining the causal influence and digraph diagram In DEMATEL, this requires three sub-steps.

Step 7a: Computation of the row $\left(R_{i}\right)$ and column $\left(D_{j}\right)$ sums

For each row $(i)$ and column $(j)$, the sum can be obtained from the total-relation matrix $(T)$, as shown below:

$$
\begin{aligned}
R_{i} & =\left[\sum_{j=1}^{n} T_{i j}\right] \forall i \\
D_{j} & =\left[\sum_{i=1}^{n} T_{i j}\right] \forall j
\end{aligned}
$$

Step 7b: Computation of the overall prominence $\left(P_{i}\right)$ and the net effect $\left(E_{i}\right)$

The overall prominence $\left(P_{i}\right)$ and the net effect $\left(E_{i}\right)$ can be obtained from the following equations:

$$
\begin{aligned}
P_{i} & =\left[R_{i}+D_{j}\right] \forall i=j \\
E_{i} & =\left[R_{i}-D_{j}\right] \forall i=j
\end{aligned}
$$

The greater the value of $P_{i}$ the greater the overall prominence (i.e., the influence, importance, and visibility) of the factor/barrier $i$ in terms of its total relationship with other factors and/or barriers. If $E_{i}>0$, then the factor/barrier $i$ is a net cause, or the foundation for other factors or barriers. These factors are known as influencing factors. If $E_{i}<0$, then factor/barrier $i$ is the net effect of other factors or barriers. These types of factors are known as resulting factors. This nomenclature is adopted from Bai and Sarkis (2013). These values may then be plotted on a two-dimensional axis for each factor or barrier (Tzeng et al., 2007). 
Step 7c: The setting of the threshold value and plotting of the digraph

The total-relation matrix $(T)$ shows how one barrier influences another. To avoid comparably negligible effects, experts, analysts, or evaluators need to set a threshold value $(\theta)$ (Liou et al., 2007). If $T_{i j} \geq \theta$, then factor/barrier $i$ influences or causes factor/barrier $j$, and a directed arrow is incorporated into the analysis. A digraph showing causal relations can be plotted from the data set: $\left(\left(R_{i}+D_{j}\right),\left(R_{i}-D_{j}\right)\right) \forall i=j$.

\section{A Real-case Application of the Proposed Model}

A case study of the barriers to the successful implementation of Industry 4.0 in French and Indian manufacturing firms illustrates the application of this method. First, following a comprehensive literature review and discussion with experts, a set of barriers was identified. Next, questionnaires were emailed to the French and Indian industry experts chosen for the case study. On receiving the responses, Grey-DEMATEL was applied and analysis was carried out, the details of which are outlined in Step 1 to Step 7c below.

Our proposed approach was applied to real Indian and French companies, as these were deemed to accurately represent the context of developing and developed economies. Our motivation for choosing companies from these differing economies was to establish where the challenges they faced differed and where they aligned. India and France differ in their readiness to exploit the benefits and opportunities presented by emerging technologies, as demonstrated in their respective $91^{\text {st }}$ and $24^{\text {th }}$ places in the Networked Readiness Index. The Networked Readiness Index assesses countries' level of readiness to utilize the benefits of emerging technologies and capitalize on the opportunities offered by digital transformation (Baller et al., 2016). A comparative analysis is, therefore, necessary in order to compare experts' perceived barriers to implementing Industry 4.0 in different institutional environments.

The chosen company based in India was Uniconverge Technologies Pvt. Ltd, established in 2013. It provides cost-effective IoT and other Industry 4.0 solutions to various manufacturing organizations. A second company, XYZ, based in France, was selected for the comparative study. XYZ was established in 1921 and has implemented Industry 4.0 practices over the last few years. XYZ has over 12 manufacturing plants. Both companies selected for the study face issues related to implementing Industry 4.0 solutions. The identification of barriers plays a vital role in the 
company managers' ability to take proactive measures to ensure the smooth implementation of Industry 4.0 solutions.

The application of the proposed approaches for each case company is given below.

Step 1: A group comprising four Uniconverge members along with two XYZ workers evaluated the direct influence of 15 barriers. These barriers were identified with the help of a literature review and discussion with a set of experts. These experts each had over five years of industry knowledge (see Section 3.1) and were familiar with the comparison of barriers using a six-point scale. These experts evaluated the direct influence of one barrier over another on a linguistic scale, ranging from no influence to a very high influence. For these 15 criteria, the initial six $(15 \times 15)$ direct

relationship matrices (four from the Indian firm's experts and two from the French) composed of linguistic variables were formed. The grey scale used for the evaluation of the direct-relation matrix is shown in Table 3.

$<$ Insert Table 3 here $>$

Step 2: We formed the six initial grey relationship matrices based on the ratings obtained from the six experts. These matrices are shown in Tables 4-9.

\section{$<$ Insert Tables 4-9 here $>$}

Step 3: In this step, we carried out the aggregation, using Eq. 2. To ensure homogeneity of judgment, we assigned equal weight to each expert. The resulting matrices are shown in Tables 10-11. It is important to note that two matrices were obtained from the averages. Table 10 shows the aggregation of the input from the four Indian experts and Table 11 shows the aggregation of the input from the two French experts.

\section{<Insert Tables 10-11 here>}

Step 4: We obtained the crisp-relation matrices (Z1 and Z2) for the Indian and French firms by using Eqs. 3-8. The matrices are shown in Tables 12 and 13. 
Step 5: We carried out normalization for the crisp-relation matrices (Z1 and Z2) by using Eq. 10 to obtain the normalized direct crisp-relation matrices (X1 and X2), which are given in Tables 14 and 15 .

\section{<Insert Tables 14-15 here >}

Step 6: We obtained the total relation matrices (T1 and T2) by using Eqs. 11 and 12, as shown in Tables 16 and 17.

\section{<Insert Tables 16-17 here>}

Step 7: We developed the causal influence and digraph diagram in DEMATEL by using the following sub-steps:

Step 7a: We determined the row $\left(R_{i}\right)$ and column $\left(D_{j}\right)$ sums for each row $i$ and column $j$ from the total relation matrices (T1 and T2) by using Eqs. 13 and 14. The row values $\left(D_{i}\right)$ represent the sum of the direct and indirect influences of implementing Industry 4.0 barrier $i$ on the other barriers. Similarly, the column values $\left(R_{j}\right)$ indicate the sum of the direct and indirect influences that barrier $j$ is under from other barriers.

Step 7b: We determined the overall prominence $\left(P_{i}\right)$ and the net effect $\left(E_{i}\right)$ for the Indian firm and French firm using Eqs. 15 and 16. These matrices are shown in Table 18. We identified the cause barriers and effect barriers (if $E_{i}>0$, then cause, otherwise effect), which are indicated in the column number. Using these values, we drew diagrams showing the overall prominence and causal relationships (Figures 2 and 3).

\section{<Insert Table 18 here $>$}

Step 7c: In order to analyze the patterns and relationships between barriers, we created diagraphs (Figures 2 and 3). A possible total of 225 relationships arise from the total matrices T1 and T2. To filter out any comparably negligible causes and effects among the barriers, we determined a 
threshold value. We calculated the threshold value $(\theta)$ by considering the mean and the standard deviation of the elements of the total matrices T1 and T2 $(\theta=\mu+\sigma)$. The arrows represent the cause barriers and effect barriers to implementing Industry 4.0 in the manufacturing industry. In the digraph, dotted lines represent two-way relationships whereas solid lines represent one-way relationships.

\section{Results and Analysis}

Three elements were analyzed in order to comprehend the findings of the research: prominent barriers, influencing barriers and resulting barriers. A ranking for each barrier is given in Table 19 and the relationships between barriers is given in Figures 2 and 3. Next, we will discuss the prominent barriers, followed by the influencing and resulting barriers.

\section{$<$ Insert Table 19>}

\subsection{Prominent Barriers}

Prominent barriers are also known as causal barriers and have a high prominence score, indicating a higher correlation with other barriers. These barriers have significant impacts on other barriers, and it is therefore crucial that managers identify and plan to resolve these barriers to allow for seamless implementation of Industry 4.0 in their organizations (Bai and Sarkis, 2013).

In both countries, 'lack of a digital strategy alongside resource scarcity (DC3)' is the most prominent factor prohibiting efficient adoption of Industry 4.0. Liao et al (2018) also suggest that only a few countries have sufficient knowledge and clarity about digital technology. For instance, according to McKinsey's report ${ }^{1}$ only $10-20 \%$ of Indian companies have a clear roadmap for undertaking digitization.

Regardless of the country analyzed, the root cause of barriers to adopting Industry 4.0 technologies is 'lack of a digital strategy alongside resource scarcity'. Therefore, managers should strategically plan to guide company actions and invest in resources which will aid the transition to Industry 4.0. Tackling the root cause of barriers to Industry 4.0 will allow companies to thrive in the digital revolution.

\footnotetext{
${ }^{1}$ https://www.thehindubusinessline.com/economy/indian-firms-moving-fast-on-road-to-industry40/article26367177.ece
} 
India and France differ in terms of their readiness to exploit the benefits and opportunities of emerging technologies, at $91^{\text {st }}$ and $24^{\text {th }}$ place respectively in the Networked Readiness Index. Despite this difference, it seems that in both contexts top management should focus on concrete plans and roadmaps in order to effectively pursue Industry 4.0 benefits. Firms' internal capabilities are resources which can be further developed in the Industry 4.0 revolution.

This result differs slightly from Aggarwal et al. (2019), who identified - by means of the DEMATEL technique - that 'management commitment' was a prominent barrier within Indian firms.

\subsection{Influencing Barriers}

The five most critical influencing factors, with crucial effects on the implementation of Industry 4.0, are identified on the basis of the highest net effect or $(R-D)$ value. In the case of the Indian firm, 'lack of standards, regulations, and forms of certification (IR6)' is the most important influencing factor, followed by the 'lack of internal digital training (C3)', 'lack of infrastructure (IR7)', 'lack of clarity regarding the economic benefit (TR2)', and 'lack of a digital strategy alongside resource scarcity (DC3)'. The digital transformation journey could be a particular challenge in developing countries, such as India, if standards, regulations, and forms of certification (IR6) are not appropriately set, since it is the most influential barrier highlighted in this study. This finding is similar to Kamble's study (2018), which also analyzed Indian firms.

This finding indicates that 'lack of standards, regulations, and forms of certification' is the barrier that most influences the non-adoption of Industry 4.0 in the case of the Indian firm. Therefore, standards and government regulation are required across Indian industries which are looking to embrace Industry 4.0 in order to reduce this barrier. Market and regulatory environments also affect the Indian case for adopting Industry 4.0 technologies.

This finding is aligned with Bogoviz et al. (2019), who state that the advancement of Industry 4.0 in developing countries has so far been carried out on a corporate level, dependent on individual corporate initiatives rather than national and coordinated policies. Because of this, market and regulatory environments are an influencing barrier.

In the French context, 'low maturity level of the desired technology (IR3)' is the most important influencing factor, followed by a 'lack of internal digital training (C3)', 'lack of standards/regulations/certification (IR6)', 'lack of digital skills (C1)', and 'risk of security 
breaches (IR2)'. These influencing factors are related to technology development and security issues. Therefore, managers should prioritize investment in infrastructure to support technological systems in order to avoid failures when implementing Industry 4.0 technologies.

'Low maturity level of the desired technology' directly affects the adoption of Industry 4.0 technologies in the French context, a barrier which could be dealt with through management actions; this differs from the Indian context, which relies on market and regulatory environments.

These findings also align with Bogoviz et al. (2019), who state that developed countries have formulated national strategies and policies to incentivize the adoption of Industry 4.0 technologies in their countries. As a consequence of this, companies from developing countries tend to have difficulties implementing Industry 4.0 technologies at the firm level, rather than problems arising from market and regulation environments, as is the case in developed countries.

Therefore, improvements in standards and government regulation would facilitate the adoption of Industry 4.0 in the Indian case, whereas infrastructure to support technological systems could promote the adoption of such technologies in the French case.

\subsection{Resulting Barriers}

The resulting barriers are the most-influenced barriers, i.e. those which are most affected by other barriers. Bai and Sarkis (2013) suggest that firms can focus on these factors after considering other factors. The top five resulting factors, with net effect or $(R-D)$ values below zero (Figure 2), are 'high investment in Industry 4.0 implementation (TR1)', 'challenge in valuechain integration (IR1)', 'risk of security breaches (IR2)', 'resistance to change (DC1)', and 'low maturity level of the desired technology (IR3)' in the Indian context.

While high investment, value-chain integration, security risks and resistance to change are critical issues, it is important to recognize that all these issues arise at later stages, at which point organizations are already internally capable of adopting and implementing Industry 4.0. These circumstances apply to developing nations, where the significant barriers are those that influence other barriers and are mainly related to internal capability issues.

In the French context, the top five resulting factors are 'ineffective change management (DC2)', 'high investment in Industry 4.0 implementation (TR1)', 'resistance to change (DC1)', 'challenges in value-chain integration (IR2)' and 'lack of a digital strategy alongside resource scarcity (DC3)'. 
As shown in Figures 2 and 3, many factors have a substantial influence on resulting factors; for example, numerous arrows point to high investment in Industry 4.0 implementation (TR1) and to challenges in value-chain integration (IR1). Firms must develop appropriate strategies to tackle different factors, and resulting factors should be considered only after the key influences have been dealt with. Thus, firms should first prioritize the reduction or the elimination of the most prominent barrier - 'lack of a digital strategy alongside resource scarcity (DC3)' - before tackling the resulting barriers; primarily 'high investment in Industry 4.0 implementation (TR1)'.

\subsection{Sensitivity Analysis}

A sensitivity analysis was conducted to investigate how cause-effect relations change by assigning different weights to the experts consulted. Due to differences in the experts' total industry experience, the results may suffer from biases. In order to ensure robustness, we conducted this analysis by assigning different weights to the experts under different scenarios. In the basic scenario, all experts are assigned equal weights. In sensitivity scenarios for the Indian respondents, the weight of one expert is two times the equal weights of the other three experts. For example, in the first scenario, the weight of the first expert is two times the equal weights of the other three experts. The cause-and-effect parameters and rankings based on the net effect for all the barriers in the Indian manufacturing industry are similar (Figure 4). In the case of the French firm, the two experts had the same number of years' experience; we therefore assigned them equal weights without further sensitivity analysis. The results of the sensitivity analysis suggest that the orders of the rankings are similar in all the scenarios, with a negligible order of exception. This shows that the results are robust and do not have any significant human bias.

\section{<Insert Figure 4 here $>$}

\section{Conclusion}

The implementation of Industry 4.0 is the prime agenda for developing as well as developed economies in the context of the manufacturing industry. To reduce the risk of failure related to implementation, 15 barriers were identified based on a comprehensive literature review and discussion with experts from both developed and developing economies. The study highlights how the impacts of these barriers are different in developed and developing economies. 
Furthermore, we examined the relationships between the barriers by utilizing a hybrid approach, a combination of Grey Set Theory and DEMATEL. This approach proved useful when integrating the perceptions and perspectives of various companies and experts, and divides a set of complex factors into cause-and-effect groups through a causal diagram and digraphs.

The factor 'lack of a digital strategy alongside resource scarcity (DC3)' emerged as the most prominent barrier in both developed and developing economies. It is therefore clear that managers should create roadmaps and plan strategically in order to guide actions and investment in resources to facilitate the transition to Industry 4.0. Tackling the root causes behind the barriers to the adoption of Industry 4.0 should prove an effective way of thriving in the digital revolution.

The most important influencing factors identified in the context of developing economies were 'lack of standards, regulations, and forms of certification (IR6)', whereas the most important influencing factor in the developed economy was the 'low maturity level of the desired technology (IR3)'. In the French context, the influencing barrier can be tackled by company management, in contrast with the Indian firm, which is reliant on market and regulatory environments. Therefore, improvements in standards and government regulation could facilitate the adoption of Industry 4.0 in the case of the Indian firm, whereas infrastructure to support technological systems could promote the adoption of Industry 4.0 technologies in the French company.

These findings are aligned with Bogoviz et al.'s 2019 study, which states that developed countries have formulated national strategies and policies for incentivizing Industry 4.0 technologies, whereas developing countries have adopted Industry 4.0 technologies on a corporate level, relying on individual corporate initiatives rather than national and coordinated policies. The influencing barriers in developed and developing countries differ due to divergent policies for the advancement of Industry 4.0.

\subsection{Contributions}

The key contributions of this paper are as follows. First, it identifies the barriers to implementing Industry 4.0 in the manufacturing industry in the context of developed and developing economies, comparing the findings based on features of each type of economy. Second, it analyzes the causal relationships between 15 barriers using Grey-DEMATEL. This technique can identify the total degree of influence each barrier has over the other barriers, and provides better decoding of uncertainty and vagueness in the responses of experts, providing improved 
analysis compared with the application of ISM techniques. Finally, it raises the issue that challenges to the diffusion of technological innovation in developing countries may prevent firms from fully benefiting from the Industry 4.0 revolution. Thus, public policies and industrial clusters should be nurtured in developing countries, focusing mainly on standards and government regulation, in order to facilitate the adoption of Industry 4.0

\subsection{Implications}

The results presented in this paper make several research contributions as well as providing implications for policy and management. The barriers identified in this study may serve as a guide for managers, as it comprehensively covers the possible barriers related to implementing Industry 4.0. Firms should formulate appropriate strategies to achieve a higher degree of success in implementation. Our results reveal that managers should consider enhancing firms' internal capabilities in order to overcome the challenges of implementing Industry 4.0. It is interesting to note that internal capability is a central issue, regardless of whether the firm is in a developed or a developing economy. In order to enhance internal capability, top management should focus, in particular, on building roadmaps and planning strategically to invest in suitable resources. Consulting companies could help firms to prioritize their allocation of resources.

Developing countries should continue to create programs to promote the transition towards Industry 4.0 technologies, in order to help firms to deal with barriers such as 'lack of standards and government regulation'.

Some limitations and concerns arising from this study provide further research opportunities. For example, our analysis is based on a limited number of experts. For a generalization of the research findings, more responses from multiple industries could be collected and analyzed. Furthermore, other MCDM techniques could be applied to enable a comparison with the results of our study. In this paper, we investigated barriers to Industry 4.0 implementation. To help overcome these barriers, future researchers could analyze different enabling factors for Industry 4.0 implementation.

\section{Acknowledgments}

The authors would like to express gratitude towards the six industry experts from the Indian and French manufacturing sector, who contributed to this study by providing their support and useful insights for the identification and comparison of the barriers, and their subsequent validation of results. 


\section{References}

Aggarwal, A., Gupta, S., \& Ojha, M. K. (2019). Evaluation of Key Challenges to Industry 4.0 in Indian Context: A DEMATEL Approach. In Advances in Industrial and Production Engineering (pp. 387-396). Springer, Singapore.

Ahlers, T., 2015. Industrie 4.0: The Big Unknown? Freudenberg IT.

Anderson, D., \& Anderson, L. A. (2010). Beyond change management: How to achieve breakthrough results through conscious change leadership (Vol. 36). John Wiley \& Sons.

Bai, C., \& Sarkis, J. (2013). A grey-based DEMATEL model for evaluating business process management critical success factors. International Journal of Production Economics, 146(1), 281292.

Baller, S., Di Battista, A., Dutta, S., \& Lanvin, B. (2016). The Networked Readiness Index 2016. The Global Information Technology Report, 3-31.

Barreto, L., Amaral, A., \& Pereira, T. (2017). Industry 4.0 implications in logistics: an overview. Procedia Manufacturing, 13, 1245-1252.

Ben-Daya, M., Hassini, E., \& Bahroun, Z. (2017). Internet of things and supply chain management: a literature review. International Journal of Production Research, 1-24.

Bogoviz A.V., Osipov V.S., Chistyakova M.K., Borisov M.Y. (2019) Comparative Analysis of Formation of Industry 4.0 in Developed and Developing Countries. In: Popkova E., Ragulina Y., Bogoviz A. (eds) Industry 4.0: Industrial Revolution of the 21st Century. Studies in Systems, Decision and Control, vol 169. Springer, Cham

Breunig, M., Kelly, R., Mathis, R., \& Wee, D. (2016). Getting the most out of Industry 4.0. Retrieved March 12, 2018, from https:/www.mckinsey.com/business-functions/operations/ourinsights/industry-40-looking-beyond-the-initial-hype

Brynjolfsson, E. (1993). The productivity paradox of information technology. Communications of the ACM, 36(12), 66-77.

Brynjolfsson, E., \& McAfee, A. (2012). Race against the machine: How the digital revolution is accelerating innovation, driving productivity, and irreversibly transforming employment and the economy. Brynjolfsson and McAfee.

Buer, S. V., Strandhagen, J. O., \& Chan, F. T. (2018). The link between Industry 4.0 and lean manufacturing: mapping current research and establishing a research agenda. International Journal of Production Research, 56(8), 2924-2940.

Buntz, B. (2016). Top 10 Barriers for Adoption of the Internet of Things. Retrieved July, 2018, from http://www.ioti.com/security/top-10-reasons-people-aren-t-embracing-iot

Chen, Z. K., Yang, S. Q., Tan, S., Zhao, H., He, L., Zhang, G., \& Yang, H. Y. (2014). The Data Allocation Strategy Based on Load in NoSQL Database. In Applied Mechanics and Materials(Vol. 513, pp. 1464-1469). Trans Tech Publications. 
Dalenogare, L. S., Benitez, G. B., Ayala, N. F., \& Frank, A. G. (2018). The expected contribution of Industry 4.0 technologies for industrial performance. International Journal of Production Economics. https://doi.org/10.1016/j.ijpe.2018.08.019

de Sousa Jabbour, A. B. L., Jabbour, C. J. C., Foropon, C., \& Godinho Filho, M. (2018b). When titans meet-Can industry 4.0 revolutionise the environmentally-sustainable manufacturing wave? The role of critical success factors. Technological Forecasting and Social Change, 132, 18-25.

de Sousa Jabbour, A. B. L., Jabbour, C. J. C., Godinho Filho, M., \& Roubaud, D. (2018a). Industry 4.0 and the circular economy: a proposed research agenda and original roadmap for sustainable operations. Annals of Operations Research, 1-14.

Deng, J. L. (1982). Control problems of grey systems. Sys. \& Contr. Lett., 1(5), 288-294.

Fettermann, D. C., Cavalcante, C. G. S., Almeida, T. D. D., \& Tortorella, G. L. (2018). How does Industry 4.0 contribute to operations management?. Journal of Industrial and Production Engineering, 35(4), 255-268.

Frank, A. G., Dalenogare, L. S., \& Ayala, N. F. (2019). Industry 4.0 technologies: Implementation patterns in manufacturing companies. International Journal of Production Economics, 210, 1526.

Geissbauer, R., Schrauf, S. \& Koch, V. (2014). Industry 4.0: Opportunities and Challenges of Industrial Internet, PricewaterhouseCoopers. Available at: https://www.pwc.nl/en/assets/documentAhlers, T., 2015. Industrie 4.0: The Big Unknown? Freudenberg IT.

Haddud, A., DeSouza, A., Khare, A., \& Lee, H. (2017). Examining potential benefits and challenges associated with the Internet of Things integration in supply chains. Journal of Manufacturing Technology Management, 28(8), 1055-1085.

Hofmann, E., \& Rüsch, M. (2017). Industry 4.0 and the current status as well as future prospects on logistics. Computers in Industry, 89, 23-34.

Horváth, D., \& Szabó, R. Z. (2019). Driving forces and barriers of Industry 4.0: Do multinational and small and medium-sized companies have equal opportunities?. Technological Forecasting and Social Change, 146, 119-132.

Hung, M., 2016. IoT Implementation and Management - from the Edge to the Cloud [WWW Document]. Gartner. URL https://www.gartner.com/technology/research/internet-ofthings/report/ (accessed 7.23.18).

Ivanov, D., Dolgui, A., \& Sokolov, B. (2018). The impact of digital technology and Industry 4.0 on the ripple effect and supply chain risk analytics. International Journal of Production Research, $1-18$.

Johnsen, R. E., \& Ford, D. (2006). Interaction capability development of smaller suppliers in relationships with larger customers. Industrial Marketing Management, 35(8), 1002-1015.

Kache, F., \& Seuring, S. (2017). Challenges and opportunities of digital information at the intersection of Big Data Analytics and supply chain management. International Journal of Operations \& Production Management, 37(1), 10-36. 
Kamble, S. S., Gunasekaran, A., \& Sharma, R. (2018). Analysis of the driving and dependence power of barriers to adopt industry 4.0 in Indian manufacturing industry. Computers in Industry, 101, 107-119.

Karadayi-Usta, S. (2019). An Interpretive Structural Analysis for Industry 4.0 Adoption Challenges. IEEE Transactions on Engineering Management.

Khan, N., Yaqoob, I., Hashem, I. A. T., Inayat, Z., Ali, M., Kamaleldin, W., ... \& Gani, A. (2014). Big data: survey, technologies, opportunities, and challenges. The Scientific World Journal, 2014.

Kiel, D., Arnold, C., \& Voigt, K. I. (2017). The influence of the Industrial Internet of Things on business models of established manufacturing companies-A business level perspective. Technovation, 68, 4-19.

Lee, H. S., Tzeng, G. H., Yeih, W., Wang, Y. J., \& Yang, S. C. (2013). Revised DEMATEL: resolving the infeasibility of DEMATEL. Applied Mathematical Modelling, 37(10-11), 67466757.

Lee, I., \& Lee, K. (2015). The Internet of Things (IoT): Applications, investments, and challenges for enterprises. Business Horizons, 58(4), 431-440.

Li, L. (2017). China's manufacturing locus in 2025: With a comparison of "Made-in-China 2025" and "Industry 4.0". Technological Forecasting and Social Change

Liao, Y., Loures, E. R., Deschamps, F., Brezinski, G., \& Venâncio, A. (2018). The impact of the fourth industrial revolution: a cross-country/region comparison. Production, 28.

Liou, J. J. H., Tzeng, G. H., and Chang, H. C. (2007). Airline safety measurement using a hybrid model, Journal of air transport management, 13(4), 243-249.

Lohr, S. (2012). The age of big data. New York Times, 11(2012).

Lu, Y. (2017). Industry 4.0: A survey on technologies, applications and open research issues. Journal of Industrial Information Integration, 6, 1-10.

Luthra, S., \& Mangla, S. K. (2018). Evaluating challenges to Industry 4.0 initiatives for supply chain sustainability in emerging economies. Process Safety and Environmental Protection, 117, 168-179.

Machado, C. G., Winrotha, M., Carlssonb, D., Almströma, P., Centerholtb, V., \& Hallin, M. (2019). Industry 4.0 readiness in manufacturing companies: challenges and enablers towards increased digitalization. way, 1(2), 3-4.

Majeed, A. A., \& Rupasinghe, T. D. (2017). Internet of Things (IoT) embedded future supply chains for industry 4.0: an assessment from an ERP-based fashion apparel and footwear industry. International Journal of Supply Chain Management, 6(1), 25-40.

Mangla, S. K., Luthra, S., Rich, N., Kumar, D., Rana, N. P., \& Dwivedi, Y. K. (2018). Enablers to implement sustainable initiatives in agri-food supply chains. International Journal of Production Economics, 203, 379-393.

McKinsey Company Quarterly (2014). The rising strategic risks of cyberattacks., http://www.mckinsey.com/business-functions/business-technology/our-insights/the-risingstrategic-risks-of-cyberattacks/ Accessed 12.04.16. 
McKinsey Digital (2016), Industry 4.0 after the initial hype. Where manufacturers are finding value and how they can best capture it, McKinsey \& Company.

Moktadir, M. A., Ali, S. M., Kusi-Sarpong, S., \& Shaikh, M. A. A. (2018). Assessing challenges for implementing Industry 4.0: Implications for process safety and environmental protection. Process Safety and Environmental Protection.

Montealegre, R. (2002). A process model of capability development: Lessons from the electronic commerce strategy at Bolsa de Valores de Guayaquil. Organization Science, 13(5), 514-531

Mrugalska, B., \& Wyrwicka, M. K. (2017). Towards lean production in industry 4.0. Procedia Engineering, 182, 466-473.

Müller, J. M., Kiel, D., \& Voigt, K. I. (2018). What Drives the Implementation of Industry 4.0? The Role of Opportunities and Challenges in the Context of Sustainability. Sustainability, 10(1), 247.

O'Halloran, D., \& Kvochko, E. (2015, January). Industrial internet of things: unleashing the potential of connected products and services. In World Economic Forum (p. 40).

Oesterreich, T. D., \& Teuteberg, F. (2016). Understanding the implications of digitisation and automation in the context of Industry 4.0: A triangulation approach and elements of a research agenda for the construction industry. Computers in Industry, 83, 121-139

Osterman, P. (1986). The impact of computers on the employment of clerks and managers. ILR Review, 39(2), 175-186.

Parente, S. L., \& Prescott, E. C. (1994). Barriers to technology adoption and development. Journal of political Economy, 102(2), 298-321.

Pereira, A. C., \& Romero, F. (2017). A review of the meanings and the implications of the Industry 4.0 concept. Procedia Manufacturing, 13, 1206-1214.

Petrillo, A., De Felice, F., Cioffi, R., \& Zomparelli, F. (2018). Fourth industrial revolution: Current practices, challenges, and opportunities. In Digital Transformation in Smart Manufacturing. InTech.

Rajesh, R., \& Ravi, V. (2015). Modeling enablers of supply chain risk mitigation in electronic supply chains: A Grey-DEMATEL approach. Computers \& Industrial Engineering, 87, 126-139.

Rossini, M., Costa, F., Tortorella, G. L., \& Portioli-Staudacher, A. (2019). The interrelation between Industry 4.0 and lean production: an empirical study on European manufacturers. The International Journal of Advanced Manufacturing Technology, 1-14.

Ryan, P. J., \& Watson, R. B. (2017). Research Challenges for the Internet of Things: What Role Can OR Play?. Systems, 5(1), 24.

Saatçioğlu, Ö. Y., Özispa, N., \& Kök, G. T. (2019). Scrutinizing the Barriers That Impede Industry 4.0 Projects: A Country-Wide Analysis for Turkey. In Agile Approaches for Successfully Managing and Executing Projects in the Fourth Industrial Revolution (pp. 294-314). IGI Global.

Schröder, C. (2016). The challenges of industry 4.0 for small and medium-sized enterprises. Friedrich-Ebert-Stiftung, Bonn

Schwab, K. (2017). The fourth industrial revolution. Crown Business. 
Si, S. L., You, X. Y., Liu, H. C., \& Zhang, P. (2018). DEMATEL technique: A systematic review of the state-of-the-art literature on methodologies and applications. Mathematical Problems in Engineering, 2018.

Stentoft, J., Jensen, K. W., Philipsen, K., \& Haug, A. (2019, January). Drivers and Barriers for Industry 4.0 Readiness and Practice: A SME Perspective with Empirical Evidence. In Proceedings of the 52nd Hawaii International Conference on System Sciences.

Stolarick, K. (1999). IT spending and firm productivity: Additional evidence from the manufacturing sector. Center for Economic Studies, US Department of Commerce, Bureau of the Census..

Tseng, M. L. (2009). A causal and effect decision making model of service quality expectation using grey-fuzzy DEMATEL approach. Expert systems with applications, 36(4), 7738-7748.

Türkeș, M. C., Oncioiu, I., Aslam, H. D., Marin-Pantelescu, A., Topor, D. I., \& Căpuşneanu, S. (2019). Drivers and Barriers in Using Industry 4.0: A Perspective of SMEs in Romania. Processes, $7(3), 153$.

Tzeng, G. H., Chiang, C. H., and Li, C. W. (2007). Evaluating intertwined effects in e-learning programs: A novel hybrid MCDM model based on factor analysis and DEMATEL, Expert systems with Applications, 32(4), 1028-1044.

Xia, X., Govindan, K., \& Zhu, Q. (2015). Analyzing internal barriers for automotive parts remanufacturers in China using grey-DEMATEL approach. Journal of Cleaner Production, 87, 811-825.

Xu, L. D., Xu, E. L., \& Li, L. (2018). Industry 4.0: state of the art and future trends. International Journal of Production Research, 56(8), 2941-2962.

Zanello, G., Fu, X., Mohnen, P., \& Ventresca, M. (2016). The creation and diffusion of innovation in developing countries: A systematic literature review. Journal of Economic Surveys, 30(5), 884912.

Zhou, K., Liu, T., \& Zhou, L. (2015, August). Industry 4.0: Towards future industrial opportunities and challenges. In Fuzzy Systems and Knowledge Discovery (FSKD), 2015 12th International Conference on (pp. 2147-2152). IEEE. 


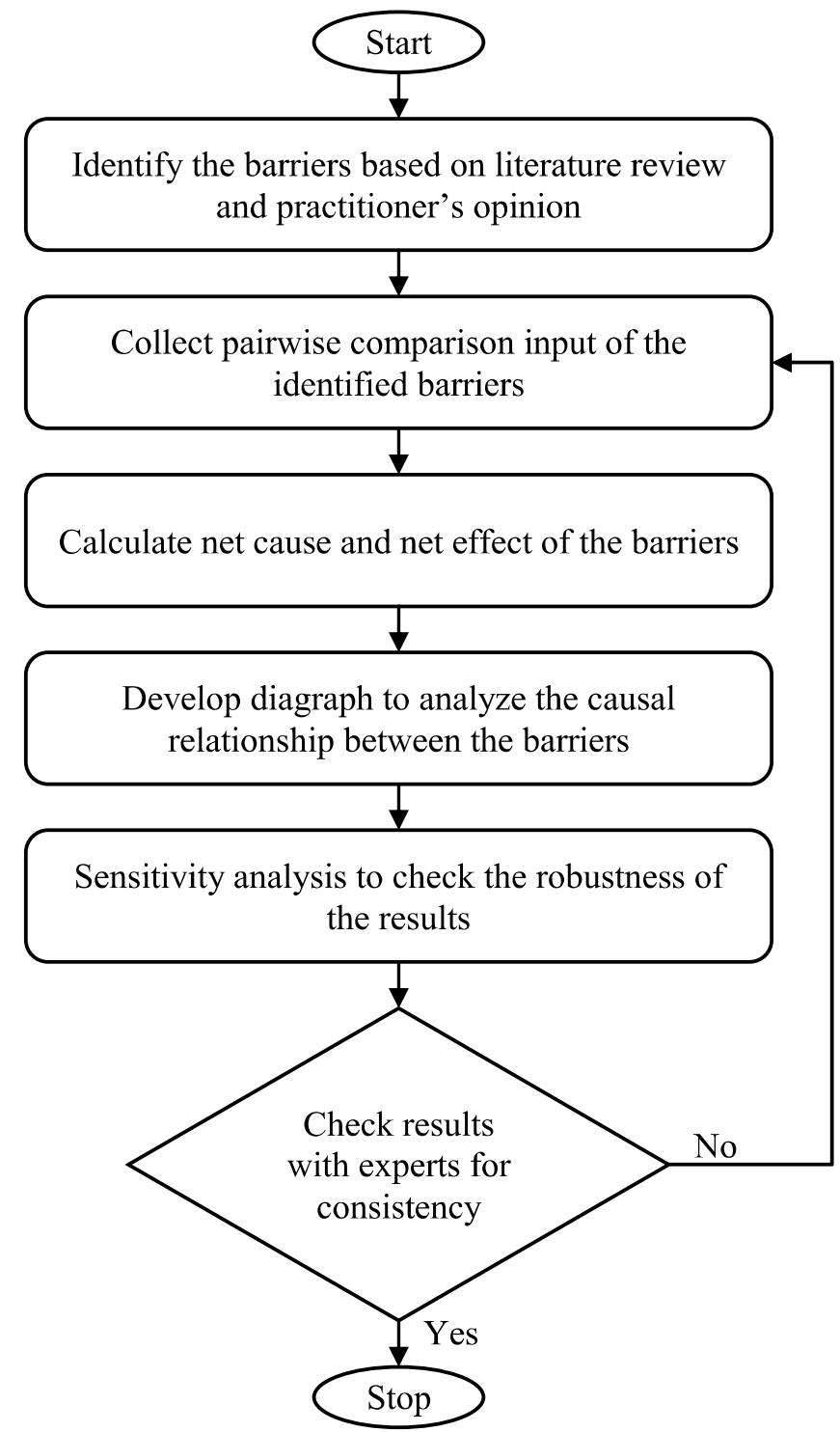

Figure 1. Proposed framework 


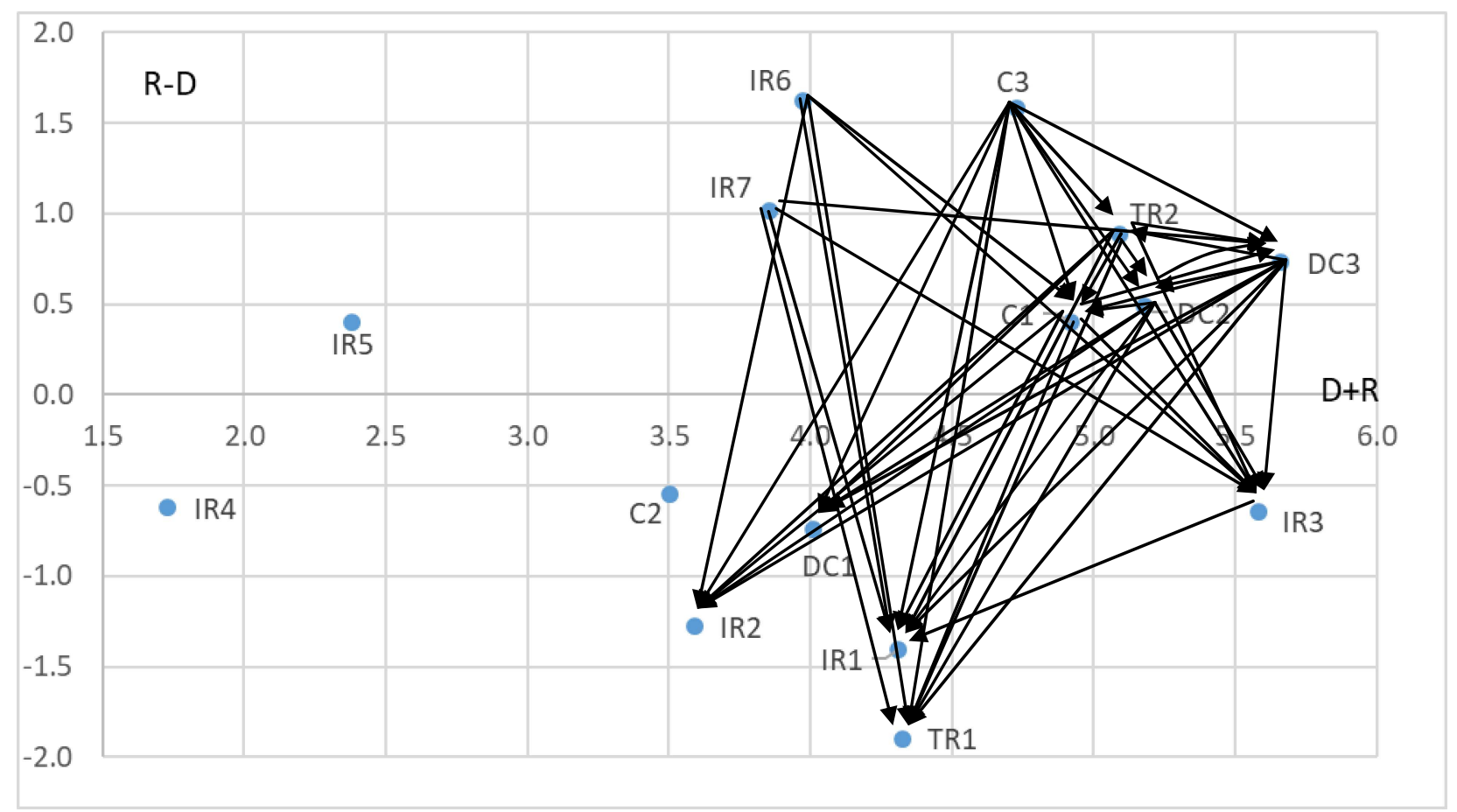

Figure 2. Diagraph showing causal relations among barriers (For India) 


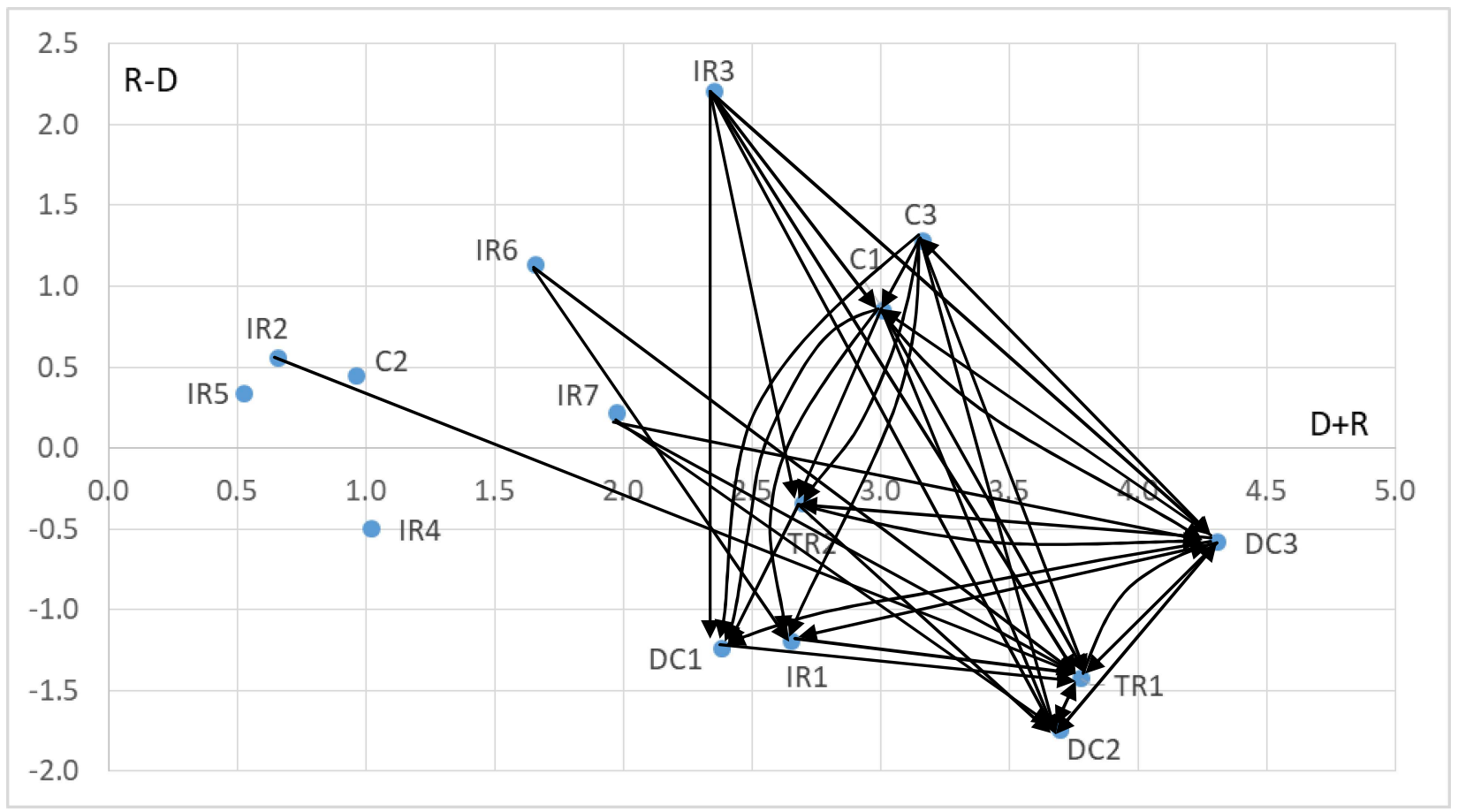

Figure 3. Diagraph showing causal relations among barriers (For France) 


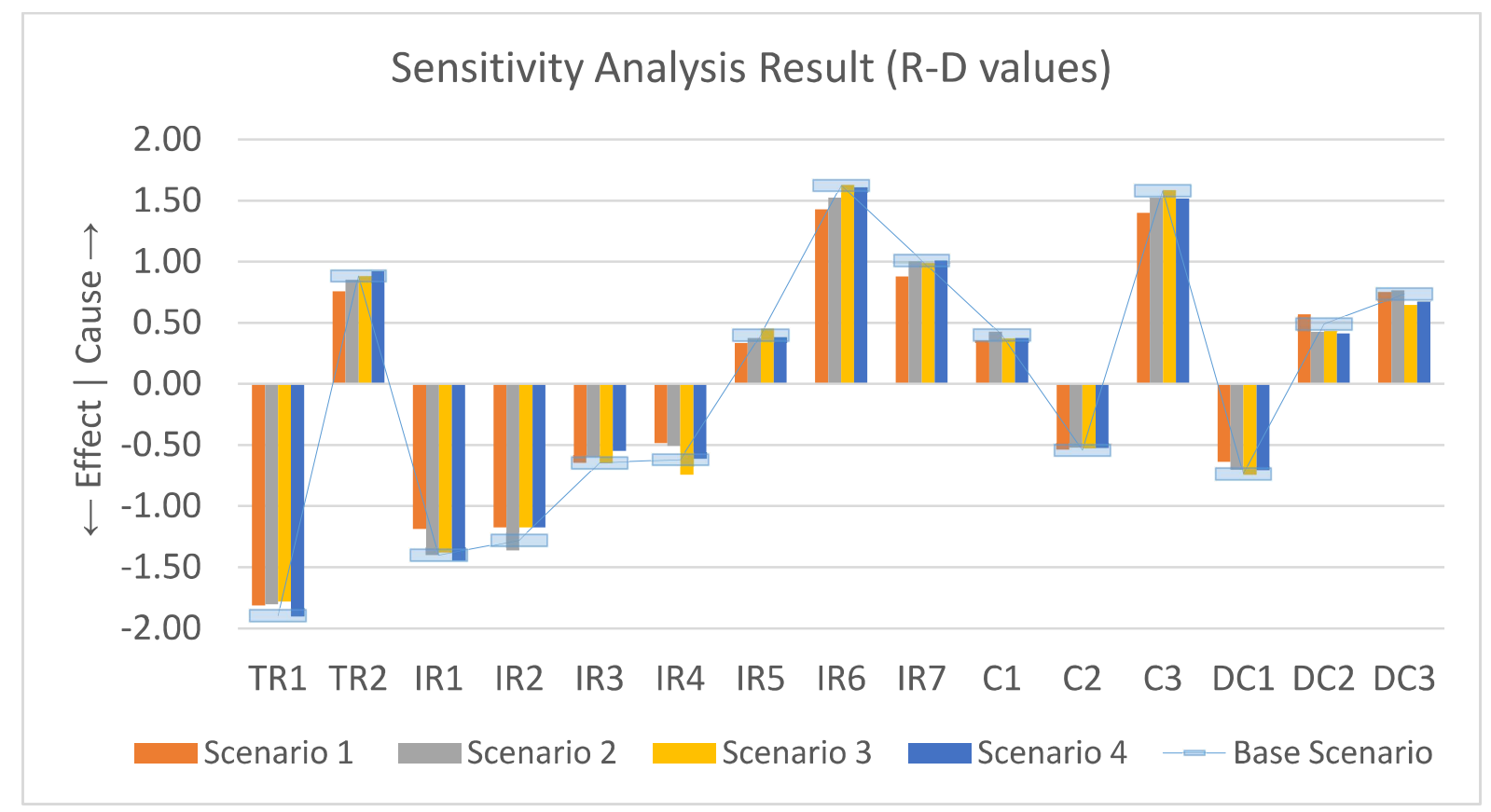

Figure 4. Sensitivity analysis result: net effect ( $\mathrm{R}$ - $\mathrm{D}$ values) of barriers 
Table1: Summary of the literature review

\begin{tabular}{|c|c|c|c|}
\hline Authors & Key contributions & Method & Industry(Country) \\
\hline $\begin{array}{l}\text { de Sousa Jabbour et } \\
\text { al., 2018a }\end{array}$ & $\begin{array}{l}\text { Eleven critical factors have been } \\
\text { identified for simultaneously } \\
\text { implementing Industry } 4.0 \text { and } \\
\text { environmentally-sustainable } \\
\text { manufacturing }\end{array}$ & $\begin{array}{l}\text { Literature } \\
\text { review }\end{array}$ & Not considered \\
\hline $\begin{array}{l}\text { de Sousa Jabbour et } \\
\text { al., } 2018 \mathrm{~b}\end{array}$ & $\begin{array}{l}\text { This work link between Industry } 4.0 \text { and } \\
\text { the circular economy (CE) }\end{array}$ & $\begin{array}{l}\text { Literature } \\
\text { review }\end{array}$ & Not considered \\
\hline Müller et al., 2018 & $\begin{array}{l}\text { Antecedents has been investigated for the } \\
\text { implementation of Industry } 4.0\end{array}$ & $\begin{array}{l}\text { Structural } \\
\text { equation } \\
\text { modelling }\end{array}$ & $\begin{array}{l}\text { Manufacturing } \\
\text { (Germany) }\end{array}$ \\
\hline $\begin{array}{l}\text { Dalenogare et al., } \\
2018\end{array}$ & $\begin{array}{l}\text { Benefits of Industry } 4.0 \text { related- } \\
\text { technologies for three industrial } \\
\text { performance metrics: } \\
\begin{array}{l}\text { operational and side-effects has been } \\
\text { analyzed }\end{array}\end{array}$ & $\begin{array}{l}\text { Regression } \\
\text { analysis }\end{array}$ & Brazil \\
\hline Kamble et al., 2018 & $\begin{array}{l}\text { Authors have analyzed the potential } \\
\text { barriers to the implementation of } \\
\text { Industry } 4.0 \text { in India }\end{array}$ & ISM & $\begin{array}{l}\text { Manufacturing } \\
\text { (India) }\end{array}$ \\
\hline Buer et al., 2018 & $\begin{array}{l}\text { The study investigates the link between } \\
\text { Industry } 4.0 \text { and lean }\end{array}$ & $\begin{array}{l}\text { Literature } \\
\text { review }\end{array}$ & Not considered \\
\hline Xu et al., 2018 & $\begin{array}{l}\text { This paper reviews the research on } \\
\text { Industry } 4.0 \text { from the industrial } \\
\text { perspective }\end{array}$ & $\begin{array}{l}\text { Literature } \\
\text { review }\end{array}$ & Not considered \\
\hline
\end{tabular}




\begin{tabular}{|c|c|c|c|}
\hline $\begin{array}{l}\text { Petrillo et al., 2018; } \\
\text { Pereira and Romero, } \\
2017\end{array}$ & $\begin{array}{l}\text { The authors have presented the main } \\
\text { good practices, challenges, and } \\
\text { opportunities related to Industry } 4.0 \\
\text { paradigm }\end{array}$ & $\begin{array}{l}\text { Literature } \\
\text { review }\end{array}$ & Not considered \\
\hline $\begin{array}{l}\text { Hofmann and Rüsch, } \\
2017\end{array}$ & $\begin{array}{l}\text { This paper discussed the opportunities of } \\
\text { Industry } 4.0 \text { in the context of logistics } \\
\text { management }\end{array}$ & $\begin{array}{l}\text { Literature } \\
\text { review }\end{array}$ & Not considered \\
\hline $\begin{array}{ll}\text { Oesterreich } & \text { and } \\
\text { Teuteberg, } 2016\end{array}$ & $\begin{array}{l}\text { A PESTEL framework has been } \\
\text { illustrated to present the implications of } \\
\text { Industry } 4.0\end{array}$ & $\begin{array}{l}\text { Content } \\
\text { analysis }\end{array}$ & $\begin{array}{l}\text { Construction } \\
\text { industry }\end{array}$ \\
\hline Zhou et al., 2015 & $\begin{array}{l}\text { This paper introduces relevant aspects of } \\
\text { Industry } 4.0 \text { in relation to strategic } \\
\text { planning, key technologies, } \\
\text { opportunities, and challenges. }\end{array}$ & $\begin{array}{l}\text { Literature } \\
\text { review }\end{array}$ & China \\
\hline
\end{tabular}

Table 2: Barriers and meaning

\begin{tabular}{|c|c|c|c|c|}
\hline No. & Barriers & Code & Meaning & References \\
\hline 1 & $\begin{array}{c}\text { High } \\
\text { investment in } \\
\text { Industry } 4.0 \\
\text { implementation }\end{array}$ & TR1 & $\begin{array}{l}\text { High amount of capital } \\
\text { investment is needed in } \\
\text { order to implement the } \\
\text { Industry } 4.0 \text { initiatives }\end{array}$ & $\begin{array}{l}\text { Geissbauer et al., 2014; Kache and } \\
\text { Seuring, 2017; Breunig et al., 2016; } \\
\text { Kamble et al., 2018; Buer et al., 2018; } \\
\text { Oesterreich and Teuteberg, 2016; }\end{array}$ \\
\hline 2 & $\begin{array}{l}\text { Lack of clarity } \\
\text { regarding the } \\
\text { economic } \\
\text { benefit }\end{array}$ & TR2 & $\begin{array}{l}\text { Productivity gains and } \\
\text { economic benefits of } \\
\text { technological } \\
\text { implementation } \\
\text { unclear due to fragmented }\end{array}$ & $\begin{array}{l}\text { Oesterreich and Teuteberg, 2016; } \\
\text { McKinsey Digital, 2016, p. 12; Kamble } \\
\text { et al., 2018; Oesterreich and Teuteberg, } \\
2016\end{array}$ \\
\hline
\end{tabular}




\begin{tabular}{|c|c|c|c|c|}
\hline & & & $\begin{array}{l}\text { implementation across the } \\
\text { value chain. }\end{array}$ & \\
\hline 3 & $\begin{array}{l}\text { Challenge in } \\
\text { value-chain } \\
\text { integration }\end{array}$ & IR1 & $\begin{array}{l}\text { Difficult to break the silos } \\
\text { across various } \\
\text { departments within the } \\
\text { organization as well as } \\
\text { among different } \\
\text { organizations in the value } \\
\text { chain }\end{array}$ & $\begin{array}{c}\text { Breunig et al., 2016; Geissbauer et al., } \\
\text { 2014; Majeed and Rupasinghe, 2017; } \\
\text { McKinsey Digital, 2016, p. 12; Kamble } \\
\text { et al., 2018; Buer et al., 2018; Petrillo } \\
\text { et al., 2018; Xu et al., 2018; Zhou et } \\
\text { al., 2015 }\end{array}$ \\
\hline 4 & $\begin{array}{l}\text { Risk of security } \\
\text { breaches }\end{array}$ & IR2 & $\begin{array}{l}\text { Highly interconnected } \\
\text { systems providing more } \\
\text { exposure for hackers to } \\
\text { attack, and firms } \\
\text { concerned about sharing } \\
\text { data with third party } \\
\text { software and service } \\
\text { providers. }\end{array}$ & $\begin{array}{c}\text { Geissbauer et al., 2014; Breunig et al., } \\
\text { 2016; Lee and Lee, 2015; McKinsey } \\
\text { Digital, 2016, p. 12; Kamble et al., } \\
\text { 2018; Buer et al., 2018; Petrillo et al., } \\
\text { 2018; Xu et al., 2018; Oesterreich and } \\
\text { Teuteberg, } 2016\end{array}$ \\
\hline 5 & $\begin{array}{l}\text { The low } \\
\text { maturity level } \\
\text { of the desired } \\
\text { technology }\end{array}$ & IR3 & $\begin{array}{l}\text { Technology pieces } \\
\text { deployed at their } \\
\text { premature stage resulting } \\
\text { in system failure as well } \\
\text { as chaos across the value } \\
\text { chain as the systems are } \\
\text { interconnected. }\end{array}$ & $\begin{array}{l}\text { Lee and Lee, 2015; Petrillo et al., 2018; } \\
\text { Xu et al., } 2018\end{array}$ \\
\hline 6 & Inequality & IR4 & $\begin{array}{l}\text { Industry } 4.0 \text { will further } \\
\text { worsen the gap between } \\
\text { rich and the poor, the } \\
\text { developed and the } \\
\text { developing nations and } \\
\text { the young and the old } \\
\text { generations }\end{array}$ & Schwab, 2017 \\
\hline 7 & $\begin{array}{l}\text { Disruption to } \\
\text { existing jobs }\end{array}$ & IR5 & $\begin{array}{l}\text { Developing nations like } \\
\text { India, China and others } \\
\text { where cheap labor is the } \\
\text { key resource would face a } \\
\text { hit with technological } \\
\text { advancements }\end{array}$ & $\begin{array}{l}\text { Haddud et al., 2017; O'Halloran and } \\
\text { Kvochko, 2015; Ryan and Watson, } \\
\text { 2017; Kamble et al., 2018; Buer et al., } \\
2018\end{array}$ \\
\hline 8 & $\begin{array}{l}\text { Lack of } \\
\text { standards, } \\
\text { regulations and } \\
\text { forms of } \\
\text { certification }\end{array}$ & IR6 & $\begin{array}{l}\text { There is lack of standards } \\
\text { and government } \\
\text { regulation across the } \\
\text { industries embracing } \\
\text { industry } 4.0\end{array}$ & $\begin{array}{c}\text { Kamble et al., 2018; Oesterreich and } \\
\text { Teuteberg, } 2016\end{array}$ \\
\hline
\end{tabular}




\begin{tabular}{|c|c|c|c|c|}
\hline 9 & $\begin{array}{c}\text { Lack of } \\
\text { infrastructure }\end{array}$ & IR7 & $\begin{array}{l}\text { Industry is not ready with } \\
\text { all the technological } \\
\text { infrastructure needed with } \\
\text { every stakeholder in the } \\
\text { value chain. Big players } \\
\text { might do but players with } \\
\text { medium to small } \\
\text { capabilities } \\
\text { struggle. }\end{array}$ & $\begin{array}{l}\text { Schröder, 2016; Buntz, 2016; Kamble } \\
\text { et al., 2018; Xu et al., } 2018\end{array}$ \\
\hline 10 & $\begin{array}{l}\text { Lack of digital } \\
\text { skills }\end{array}$ & $\mathrm{C} 1$ & $\begin{array}{l}\text { Employees and the } \\
\text { workers in the industry } \\
\text { need training and } \\
\text { development to upgrade } \\
\text { their technical skills set }\end{array}$ & $\begin{array}{c}\text { Hung, 2016; Breunig et al., 2016; } \\
\text { Geissbauer et al., 2014; McKinsey } \\
\text { Digital, 2016, p. 12; Kamble et al., } \\
\text { 2018; Petrillo et al., 2018; Oesterreich } \\
\text { and Teuteberg, } 2016\end{array}$ \\
\hline 11 & $\begin{array}{l}\text { Challenges in } \\
\text { ensuring data } \\
\text { quality }\end{array}$ & $\mathrm{C} 2$ & $\begin{array}{l}\text { Large volume of data } \\
\text { gather through various } \\
\text { technology used in } \\
\text { Industry } 4.0 \text { leads to } \\
\text { difficulty in extract the } \\
\text { useful data. }\end{array}$ & $\begin{array}{c}\text { Chen et al., 2014; Lohr, 2012; Khan et } \\
\text { al.,2014; Buer et al., 2018; Xu et al., } \\
\text { 2018; Zhou et al., } 2015\end{array}$ \\
\hline 12 & $\begin{array}{l}\text { Lack of internal } \\
\text { digital culture } \\
\text { and training }\end{array}$ & C3 & $\begin{array}{l}\text { An internal culture to } \\
\text { embrace technological } \\
\text { advancements has to be } \\
\text { nurtured from top to } \\
\text { bottom in the organization } \\
\text { and make the teams } \\
\text { technology -ready. }\end{array}$ & $\begin{array}{c}\text { Breunig et al., 2016; de Sousa Jabbour } \\
\text { et al., 2018(a,b) }\end{array}$ \\
\hline 13 & $\begin{array}{l}\text { Resistance to } \\
\text { change }\end{array}$ & DC1 & $\begin{array}{l}\text { Firms performing } \\
\text { operations in conventional } \\
\text { ways for years have a } \\
\text { natural tendency to resist } \\
\text { the changes }\end{array}$ & $\begin{array}{l}\text { Haddud et al., 2017; Lee and Lee, } \\
\text { 2015; Schröder, } 2016\end{array}$ \\
\hline 14 & $\begin{array}{l}\text { Ineffective } \\
\text { change } \\
\text { management }\end{array}$ & DC2 & $\begin{array}{l}\text { Ineffective management } \\
\text { of changing processes } \\
\text { employees, executives, } \\
\text { third party channel } \\
\text { partners, value chain } \\
\text { members. }\end{array}$ & $\begin{array}{l}\text { Anderson and Anderson, 2010; } \\
\text { de Sousa Jabbour et al., 2018(a,b); } \\
\text { Müller et al., } 2018\end{array}$ \\
\hline 15 & $\begin{array}{l}\text { Lack of a } \\
\text { digital strategy } \\
\text { alongside } \\
\text { resource }\end{array}$ & DC3 & $\begin{array}{l}\text { Firms who have no } \\
\text { strategical roadmap to } \\
\text { analyze, develop and } \\
\text { execute the capability }\end{array}$ & $\begin{array}{c}\text { Schröder, 2016; Ahlers, 2015; Petrillo } \\
\text { et al., } 2018\end{array}$ \\
\hline
\end{tabular}


scarcity

building exercise and firms lacking resources to do so would suffer in

Industry 4.0 environment

Table 3: Linguistic scale and corresponding grey values.

\begin{tabular}{|c|c|}
\hline Linguistic terms & Grey values \\
\hline No influence $(\mathrm{N})$ & {$[0,0]$} \\
\hline Very low influence $(\mathrm{VL})$ & {$[0,1]$} \\
\hline Low influence $(\mathrm{L})$ & {$[1,2]$} \\
\hline Medium influence $(\mathrm{M})$ & {$[2,3]$} \\
\hline High influence $(\mathrm{H})$ & {$[3,4]$} \\
\hline Very high influence $(\mathrm{VH})$ & {$[4,5]$} \\
\hline
\end{tabular}

Table 4: The direct-relation matrix for implementing Industry 4.0 by Expert 1 .

\begin{tabular}{|c|c|c|c|c|c|c|c|c|c|c|c|c|c|c|c|}
\hline & TR1 & TR2 & IR1 & IR2 & IR3 & IR4 & IR5 & IR6 & IR7 & C1 & C2 & C3 & DC1 & DC2 & DC3 \\
\hline TR1 & {$[0,0]$} & {$[0,0]$} & {$[0,0]$} & {$[0,0]$} & {$[3,4]$} & {$[0,0]$} & {$[0,0]$} & {$[2,3]$} & {$[1,2]$} & {$[0,0]$} & {$[0,0]$} & {$[0,0]$} & {$[0,0]$} & {$[0,0]$} & {$[0,0]$} \\
\hline TR2 & {$[3,4]$} & {$[0,0]$} & {$[3,4]$} & {$[4,5]$} & {$[3,4]$} & {$[0,0]$} & {$[0,0]$} & {$[0,0]$} & {$[2,3]$} & {$[2,3]$} & {$[0,0]$} & {$[4,5]$} & {$[3,4]$} & {$[3,4]$} & {$[3,4]$} \\
\hline IR1 & {$[2,3]$} & {$[0,1]$} & {$[0,0]$} & {$[3,4]$} & {$[3,4]$} & {$[0,0]$} & {$[2,3]$} & {$[1,2]$} & {$[1,2]$} & {$[1,2]$} & {$[2,3]$} & {$[1,2]$} & {$[4,5]$} & {$[2,3]$} & {$[3,4]$} \\
\hline IR2 & {$[1,2]$} & {$[0,0]$} & {$[4,5]$} & {$[0,0]$} & {$[3,4]$} & {$[0,0]$} & {$[0,0]$} & {$[3,4]$} & {$[2,3]$} & {$[1,2]$} & {$[1,2]$} & {$[1,2]$} & {$[1,2]$} & {$[1,2]$} & {$[1,2]$} \\
\hline IR3 & {$[0,0]$} & {$[4,5]$} & {$[4,5]$} & {$[4,5]$} & {$[0,0]$} & {$[0,0]$} & {$[2,3]$} & {$[2,3]$} & {$[1,2]$} & {$[3,4]$} & {$[3,4]$} & {$[3,4]$} & {$[1,2]$} & {$[1,2]$} & {$[1,2]$} \\
\hline IR4 & {$[0,0]$} & {$[0,0]$} & {$[0,0]$} & {$[0,0]$} & {$[0,0]$} & {$[0,0]$} & {$[0,0]$} & {$[0,0]$} & {$[0,0]$} & {$[0,0]$} & {$[0,0]$} & {$[0,0]$} & {$[3,4]$} & {$[2,3]$} & {$[0,0]$} \\
\hline IR5 & {$[2,3]$} & {$[0,0]$} & {$[3,4]$} & {$[4,5]$} & {$[3,4]$} & {$[4,5]$} & {$[0,0]$} & {$[0,0]$} & {$[1,2]$} & {$[2,3]$} & {$[1,2]$} & {$[2,3]$} & {$[1,2]$} & {$[0,0]$} & {$[0,0]$} \\
\hline IR6 & {$[3,4]$} & {$[3,4]$} & {$[3,4]$} & {$[4,5]$} & {$[3,4]$} & {$[0,0]$} & {$[1,2]$} & {$[0,0]$} & {$[3,4]$} & {$[3,4]$} & {$[3,4]$} & {$[3,4]$} & {$[3,4]$} & {$[3,4]$} & {$[3,4]$} \\
\hline IR7 & {$[3,4]$} & {$[3,4]$} & {$[3,4]$} & {$[3,4]$} & {$[1,2]$} & {$[0,0]$} & {$[1,2]$} & {$[1,2]$} & {$[0,0]$} & {$[3,4]$} & {$[3,4]$} & {$[3,4]$} & {$[3,4]$} & {$[3,4]$} & {$[3,4]$} \\
\hline C1 & {$[3,4]$} & {$[4,5]$} & {$[0,1]$} & {$[3,4]$} & {$[3,4]$} & {$[3,4]$} & {$[3,4]$} & {$[3,4]$} & {$[3,4]$} & {$[0,0]$} & {$[3,4]$} & {$[2,3]$} & {$[1,2]$} & {$[0,0]$} & {$[2,3]$} \\
\hline C2 & {$[3,4]$} & {$[1,2]$} & {$[3,4]$} & {$[1,2]$} & {$[3,4]$} & {$[0,0]$} & {$[1,2]$} & {$[2,3]$} & {$[2,3]$} & {$[1,2]$} & {$[0,0]$} & {$[0,0]$} & {$[0,0]$} & {$[0,0]$} & {$[0,0]$} \\
\hline C3 & {$[3,4]$} & {$[3,4]$} & {$[3,4]$} & {$[3,4]$} & {$[3,4]$} & {$[2,3]$} & {$[4,5]$} & {$[3,4]$} & {$[3,4]$} & {$[4,5]$} & {$[3,4]$} & {$[0,0]$} & {$[3,4]$} & {$[2,3]$} & {$[2,3]$} \\
\hline DC1 & {$[2,3]$} & {$[0,1]$} & {$[3,4]$} & {$[3,4]$} & {$[3,4]$} & {$[2,3]$} & {$[0,1]$} & {$[0,1]$} & {$[0,1]$} & {$[0,1]$} & {$[2,3]$} & {$[1,2]$} & {$[0,0]$} & {$[3,4]$} & {$[3,4]$} \\
\hline DC2 & {$[2,3]$} & {$[3,4]$} & {$[1,2]$} & {$[0,1]$} & {$[3,4]$} & {$[0,0]$} & {$[1,2]$} & {$[3,4]$} & {$[3,4]$} & {$[3,4]$} & {$[2,3]$} & {$[3,4]$} & {$[3,4]$} & {$[0,0]$} & {$[4,5]$} \\
\hline DC3 & {$[3,4]$} & {$[3,4]$} & {$[3,4]$} & {$[2,3]$} & {$[3,4]$} & {$[0,0]$} & {$[3,4]$} & {$[3,4]$} & {$[3,4]$} & {$[3,4]$} & {$[1,2]$} & {$[3,4]$} & {$[3,4]$} & {$[3,4]$} & {$[0,0]$} \\
\hline
\end{tabular}

Table 5: The direct-relation matrix for implementing Industry 4.0 by Expert 2.

\begin{tabular}{|l|l|l|l|l|l|l|l|l|l|l|l|l|l|l|l|}
\hline & TR1 & TR2 & IR1 & IR2 & IR3 & IR4 & IR5 & IR6 & IR7 & C1 & C2 & C3 & DC1 & DC2 & DC3 \\
\hline TR1 & {$[0,0]$} & {$[0,1]$} & {$[3,4]$} & {$[3,4]$} & {$[2,3]$} & {$[0,0]$} & {$[0,0]$} & {$[1,2]$} & {$[0,0]$} & {$[0,1]$} & {$[3,4]$} & {$[0,1]$} & {$[3,4]$} & {$[3,4]$} & {$[0,1]$} \\
\hline TR2 & {$[4,5]$} & {$[0,0]$} & {$[3,4]$} & {$[1,2]$} & {$[2,3]$} & {$[1,2]$} & {$[3,4]$} & {$[3,4]$} & {$[2,3]$} & {$[2,3]$} & {$[1,2]$} & {$[2,3]$} & {$[3,4]$} & {$[2,3]$} & {$[3,4]$} \\
\hline IR1 & {$[1,2]$} & {$[2,3]$} & {$[0,0]$} & {$[2,3]$} & {$[2,3]$} & {$[1,2]$} & {$[1,2]$} & {$[1,2]$} & {$[1,2]$} & {$[0,1]$} & {$[2,3]$} & {$[1,2]$} & {$[3,4]$} & {$[1,2]$} & {$[1,2]$} \\
\hline IR2 & {$[1,2]$} & {$[1,2]$} & {$[1,2]$} & {$[0,0]$} & {$[4,5]$} & {$[0,0]$} & {$[0,0]$} & {$[0,0]$} & {$[1,2]$} & {$[0,1]$} & {$[4,5]$} & {$[0,1]$} & {$[0,1]$} & {$[1,2]$} & {$[2,3]$} \\
\hline IR3 & {$[3,4]$} & {$[3,4]$} & {$[2,3]$} & {$[3,4]$} & {$[0,0]$} & {$[0,0]$} & {$[0,1]$} & {$[3,4]$} & {$[2,3]$} & {$[2,3]$} & {$[3,4]$} & {$[0,1]$} & {$[1,2]$} & {$[3,4]$} & {$[3,4]$} \\
\hline IR4 & {$[0,1]$} & {$[1,2]$} & {$[0,1]$} & {$[1,2]$} & {$[1,2]$} & {$[0,0]$} & {$[2,3]$} & {$[0,1]$} & {$[0,1]$} & {$[0,1]$} & {$[0,1]$} & {$[0,1]$} & {$[0,1]$} & {$[0,1]$} & {$[0,1]$} \\
\hline IR5 & {$[3,4]$} & {$[1,2]$} & {$[3,4]$} & {$[0,1]$} & {$[0,1]$} & {$[3,4]$} & {$[0,0]$} & {$[0,1]$} & {$[1,2]$} & {$[4,5]$} & {$[3,4]$} & {$[1,2]$} & {$[4,5]$} & {$[2,3]$} & {$[1,2]$} \\
\hline IR6 & {$[3,4]$} & {$[2,3]$} & {$[3,4]$} & {$[4,5]$} & {$[2,3]$} & {$[0,1]$} & {$[1,2]$} & {$[0,0]$} & {$[2,3]$} & {$[3,4]$} & {$[3,4]$} & {$[2,3]$} & {$[0,1]$} & {$[3,4]$} & {$[3,4]$} \\
\hline IR7 & {$[3,4]$} & {$[2,3]$} & {$[2,3]$} & {$[3,4]$} & {$[3,4]$} & {$[0,1]$} & {$[1,2]$} & {$[2,3]$} & {$[0,0]$} & {$[3,4]$} & {$[2,3]$} & {$[3,4]$} & {$[0,1]$} & {$[1,2]$} & {$[2,3]$} \\
\hline C1 & {$[3,4]$} & {$[3,4]$} & {$[3,4]$} & {$[4,5]$} & {$[3,4]$} & {$[1,2]$} & {$[4,5]$} & {$[2,3]$} & {$[0,1]$} & {$[0,0]$} & {$[3,4]$} & {$[1,2]$} & {$[3,4]$} & {$[1,2]$} & {$[1,2]$} \\
\hline C2 & {$[3,4]$} & {$[1,2]$} & {$[3,4]$} & {$[3,4]$} & {$[4,5]$} & {$[0,0]$} & {$[0,0]$} & {$[0,1]$} & {$[1,2]$} & {$[1,2]$} & {$[0,0]$} & {$[4,5]$} & {$[3,0]$} & {$[2,3]$} & {$[2,3]$} \\
\hline
\end{tabular}




\begin{tabular}{|c|c|c|c|c|c|c|c|c|c|c|c|c|c|c|c|}
\hline C3 & {$[0,1]$} & {$[3,4]$} & {$[3,4]$} & {$[4,5]$} & {$[3,4]$} & {$[0,1]$} & {$[3,4]$} & {$[2,3]$} & {$[1,2]$} & {$[3,4]$} & {$[3,4]$} & {$[0,0]$} & {$[3,4]$} & {$[2,3]$} & {$[4,5]$} \\
\hline DC1 & {$[3,4]$} & {$[0,1]$} & {$[3,4]$} & {$[1,2]$} & {$[2,3]$} & {$[0,1]$} & {$[3,4]$} & {$[0,1]$} & {$[2,3]$} & {$[3,4]$} & {$[1,2]$} & {$[1,2]$} & {$[0,0]$} & {$[1,2]$} & {$[3,4]$} \\
\hline DC2 & {$[3,4]$} & {$[2,3]$} & {$[3,4]$} & {$[2,3]$} & {$[2,3]$} & {$[3,3]$} & {$[2,3]$} & {$[1,2]$} & {$[2,3]$} & {$[1,3]$} & {$[2,3]$} & {$[2,3]$} & {$[4,5]$} & {$[0,0]$} & {$[2,3]$} \\
\hline DC3 & {$[3,4]$} & {$[3,4]$} & {$[3,4]$} & {$[3,4]$} & {$[3,4]$} & {$[2,2]$} & {$[2,3]$} & {$[2,3]$} & {$[2,3]$} & {$[4,5]$} & {$[1,2]$} & {$[3,4]$} & {$[3,4]$} & {$[4,5]$} & {$[0,0]$} \\
\hline
\end{tabular}

Table 6: The direct-relation matrix for implementing Industry 4.0 by Expert 3.

\begin{tabular}{|c|c|c|c|c|c|c|c|c|c|c|c|c|c|c|c|}
\hline & TR1 & TR2 & IR1 & IR2 & IR3 & IR4 & IR5 & IR6 & IR7 & C1 & C2 & C3 & DC1 & DC2 & DC3 \\
\hline TR1 & {$[0,0]$} & {$[0,1]$} & {$[0,0]$} & {$[0,0]$} & {$[2,3]$} & {$[4,5]$} & {$[0,0]$} & {$[0,0]$} & {$[3,4]$} & {$[0,0]$} & {$[0,0]$} & {$[0,0]$} & {$[0,0]$} & {$[2,3]$} & {$[4,5]$} \\
\hline TR2 & {$[0,1]$} & {$[0,0]$} & {$[0,1]$} & {$[4,5]$} & {$[2,3]$} & {$[2,3]$} & {$[0,0]$} & {$[1,2]$} & {$[1,2]$} & {$[4,5]$} & {$[3,4]$} & {$[0,0]$} & {$[4,5]$} & {$[4,5]$} & {$[4,5]$} \\
\hline IR1 & {$[3,4]$} & {$[1,2]$} & {$[0,0]$} & {$[0,0]$} & {$[2,3]$} & {$[0,0]$} & {$[0,0]$} & {$[0,0]$} & {$[0,1]$} & {$[0,0]$} & {$[0,0]$} & {$[0,0]$} & {$[1,2]$} & {$[1,2]$} & {$[0,0]$} \\
\hline IR2 & {$[3,4]$} & {$[0,0]$} & {$[1,2]$} & {$[0,0]$} & {$[4,5]$} & {$[0,0]$} & {$[0,0]$} & {$[0,0]$} & {$[0,0]$} & {$[0,0]$} & {$[0,0]$} & {$[0,0]$} & {$[0,1]$} & {$[0,0]$} & {$[0,0]$} \\
\hline IR3 & {$[4,5]$} & {$[3,4]$} & {$[0,0]$} & {$[0,0]$} & {$[0,0]$} & {$[0,0]$} & {$[0,0]$} & {$[2,3]$} & {$[2,3]$} & {$[3,4]$} & {$[3,4]$} & {$[1,2]$} & {$[1,2]$} & {$[1,2]$} & {$[3,4]$} \\
\hline IR4 & {$[0,0]$} & {$[0,0]$} & {$[4,4]$} & {$[0,0]$} & {$[1,2]$} & {$[0,0]$} & {$[0,0]$} & {$[0,1]$} & {$[0,1]$} & {$[0,0]$} & {$[0,0]$} & {$[0,0]$} & {$[0,0]$} & {$[0,0]$} & {$[0,0]$} \\
\hline IR5 & {$[0,0]$} & {$[0,0]$} & {$[0,0]$} & {$[0,0]$} & {$[0,1]$} & {$[0,0]$} & {$[0,0]$} & {$[0,0]$} & {$[0,0]$} & {$[1,2]$} & {$[0,0]$} & {$[0,0]$} & {$[3,4]$} & {$[3,4]$} & {$[0,0]$} \\
\hline IR6 & {$[3,4]$} & {$[2,3]$} & {$[5,5]$} & {$[3,4]$} & {$[2,3]$} & {$[0,0]$} & {$[0,0]$} & {$[0,0]$} & {$[3,4]$} & {$[4,5]$} & {$[0,0]$} & {$[2,3]$} & {$[0,0]$} & {$[0,1]$} & {$[0,1]$} \\
\hline IR7 & {$[4,5]$} & {$[0,1]$} & {$[2,3]$} & {$[3,0]$} & {$[3,4]$} & {$[0,0]$} & {$[0,0]$} & {$[0,1]$} & {$[0,0]$} & {$[3,4]$} & {$[0,0]$} & {$[0,1]$} & {$[0,0]$} & {$[3,4]$} & {$[3,4]$} \\
\hline C1 & {$[3,4]$} & {$[3,4]$} & {$[2,3]$} & {$[0,1]$} & {$[3,4]$} & {$[3,4]$} & {$[0,1]$} & {$[0,0]$} & {$[0,0]$} & {$[0,0]$} & {$[0,1]$} & {$[0,3]$} & {$[2,3]$} & {$[3,4]$} & {$[4,5]$} \\
\hline C2 & {$[1,2]$} & {$[1,2]$} & {$[2,3]$} & {$[0,0]$} & {$[4,5]$} & {$[0,0]$} & {$[0,0]$} & {$[0,0]$} & {$[0,0]$} & {$[0,0]$} & {$[0,0]$} & {$[0,0]$} & {$[0,0]$} & {$[0,1]$} & {$[2,3]$} \\
\hline C3 & {$[3,4]$} & {$[3,4]$} & {$[3,4]$} & {$[0,1]$} & {$[3,4]$} & {$[0,0]$} & {$[0,0]$} & {$[0,1]$} & {$[0,1]$} & {$[2,3]$} & {$[1,2]$} & {$[0,0]$} & {$[4,5]$} & {$[3,4]$} & {$[4,5]$} \\
\hline DC1 & {$[4,5]$} & {$[0,0]$} & {$[3,4]$} & {$[3,4]$} & {$[2,3]$} & {$[1,2]$} & {$[0,0]$} & {$[0,0]$} & {$[0,0]$} & {$[0,0]$} & {$[2,3]$} & {$[0,0]$} & {$[0,0]$} & {$[0,0]$} & {$[0,1]$} \\
\hline DC2 & {$[3,4]$} & {$[0,1]$} & {$[3,4]$} & {$[4,5]$} & {$[3,4]$} & {$[3,4]$} & {$[0,1]$} & {$[0,0]$} & {$[0,0]$} & {$[3,4]$} & {$[4,5]$} & {$[1,2]$} & {$[3,4]$} & {$[0,0]$} & {$[2,3]$} \\
\hline DC3 & {$[0,1]$} & {$[4,5]$} & {$[3,4]$} & {$[3,4]$} & {$[3,4]$} & {$[2,3]$} & {$[0,0]$} & {$[0,0]$} & {$[0,0]$} & {$[4,5]$} & {$[2,3]$} & {$[3,4]$} & {$[3,4]$} & {$[4,5]$} & {$[0,0]$} \\
\hline
\end{tabular}

Table 7: The direct-relation matrix for implementing Industry 4.0 by Expert 4 .

\begin{tabular}{|c|c|c|c|c|c|c|c|c|c|c|c|c|c|c|c|}
\hline & TR1 & TR2 & IR1 & IR2 & IR3 & IR4 & IR5 & IR6 & IR7 & C1 & C2 & C3 & DC1 & DC2 & DC3 \\
\hline TR1 & {$[0,0]$} & {$[0,1]$} & {$[0,0]$} & {$[0,0]$} & {$[0,0]$} & {$[4,5]$} & {$[0,1]$} & {$[0,1]$} & {$[2,3]$} & {$[0,1]$} & {$[0,0]$} & {$[0,1]$} & {$[0,0]$} & {$[0,1]$} & {$[3,4]$} \\
\hline TR2 & {$[2,3]$} & {$[0,0]$} & {$[3,4]$} & {$[4,5]$} & {$[4,5]$} & {$[3,4]$} & {$[0,0]$} & {$[1,2]$} & {$[1,2]$} & {$[3,4]$} & {$[3,4]$} & {$[0,0]$} & {$[3,4]$} & {$[4,5]$} & {$[4,5]$} \\
\hline IR1 & {$[3,4]$} & {$[1,2]$} & {$[0,0]$} & {$[0,0]$} & {$[0,0]$} & {$[0,0]$} & {$[0,0]$} & {$[0,1]$} & {$[0,1]$} & {$[0,0]$} & {$[0,0]$} & {$[0,0]$} & {$[1,2]$} & {$[1,2]$} & {$[0,0]$} \\
\hline IR2 & {$[3,4]$} & {$[0,1]$} & {$[1,2]$} & {$[0,0]$} & {$[3,3]$} & {$[0,0]$} & {$[0,0]$} & {$[0,0]$} & {$[0,0]$} & {$[0,0]$} & {$[0,0]$} & {$[0,0]$} & {$[0,1]$} & {$[0,0]$} & {$[0,0]$} \\
\hline IR3 & {$[4,5]$} & {$[2,3]$} & {$[0,0]$} & {$[0,0]$} & {$[0,0]$} & {$[0,0]$} & {$[0,0]$} & {$[0,1]$} & {$[0,0]$} & {$[3,4]$} & {$[3,4]$} & {$[1,2]$} & {$[1,2]$} & {$[2,3]$} & {$[1,2]$} \\
\hline IR4 & {$[0,0]$} & {$[0,0]$} & {$[3,4]$} & {$[3,4]$} & {$[0,0]$} & {$[0,0]$} & {$[0,0]$} & {$[0,1]$} & {$[0,1]$} & {$[0,0]$} & {$[3,4]$} & {$[0,0]$} & {$[0,0]$} & {$[0,0]$} & {$[0,0]$} \\
\hline IR5 & {$[0,0]$} & {$[0,0]$} & {$[0,0]$} & {$[0,0]$} & {$[1,2]$} & {$[0,0]$} & {$[0,0]$} & {$[0,0]$} & {$[0,0]$} & {$[0,0]$} & {$[0,0]$} & {$[0,0]$} & {$[3,4]$} & {$[3,4]$} & {$[0,0]$} \\
\hline IR6 & {$[3,4]$} & {$[2,3]$} & {$[4,5]$} & {$[3,4]$} & {$[3,4]$} & {$[0,0]$} & {$[0,0]$} & {$[0,0]$} & {$[3,4]$} & {$[3,4]$} & {$[0,0]$} & {$[2,3]$} & {$[0,0]$} & {$[0,1]$} & {$[0,1]$} \\
\hline IR7 & {$[4,5]$} & {$[0,1]$} & {$[2,3]$} & {$[3,4]$} & {$[3,4]$} & {$[0,0]$} & {$[0,0]$} & {$[0,1]$} & {$[0,0]$} & {$[1,2]$} & {$[0,0]$} & {$[0,1]$} & {$[0,0]$} & {$[3,4]$} & {$[3,4]$} \\
\hline C1 & {$[4,5]$} & {$[3,4]$} & {$[2,3]$} & {$[0,1]$} & {$[0,1]$} & {$[3,4]$} & {$[0,1]$} & {$[0,0]$} & {$[0,0]$} & {$[0,0]$} & {$[0,1]$} & {$[2,3]$} & {$[2,3]$} & {$[3,4]$} & {$[4,5]$} \\
\hline C2 & {$[1,2]$} & {$[1,2]$} & {$[2,3]$} & {$[0,0]$} & {$[0,0]$} & {$[0,0]$} & {$[0,0]$} & {$[0,0]$} & {$[0,0]$} & {$[0,0]$} & {$[0,0]$} & {$[0,0]$} & {$[0,0]$} & {$[1,2]$} & {$[1,2]$} \\
\hline C3 & {$[3,4]$} & {$[3,4]$} & {$[3,4]$} & {$[1,2]$} & {$[2,3]$} & {$[0,0]$} & {$[0,0]$} & {$[0,1]$} & {$[0,1]$} & {$[4,5]$} & {$[1,2]$} & {$[0,0]$} & {$[4,5]$} & {$[3,4]$} & {$[4,5]$} \\
\hline DC1 & {$[4,5]$} & {$[2,3]$} & {$[3,4]$} & {$[0,0]$} & {$[2,3]$} & {$[0,0]$} & {$[2,3]$} & {$[0,0]$} & {$[0,0]$} & {$[0,0]$} & {$[0,0]$} & {$[0,0]$} & {$[0,0]$} & {$[0,1]$} & {$[0,1]$} \\
\hline DC2 & {$[3,4]$} & {$[0,1]$} & {$[3,4]$} & {$[3,4]$} & {$[4,5]$} & {$[2,3]$} & {$[0,1]$} & {$[0,0]$} & {$[0,0]$} & {$[3,4]$} & {$[3,4]$} & {$[3,4]$} & {$[2,3]$} & {$[0,0]$} & {$[2,3]$} \\
\hline DC3 & {$[0,1]$} & {$[4,5]$} & {$[3,4]$} & {$[3,4]$} & {$[3,4]$} & {$[0,0]$} & {$[0,0]$} & {$[0,0]$} & {$[0,0]$} & {$[4,5]$} & {$[0,1]$} & {$[3,4]$} & {$[3,4]$} & {$[4,5]$} & {$[0,0]$} \\
\hline
\end{tabular}


Table 8: The direct-relation matrix for implementing Industry 4.0 by Expert 5.

\begin{tabular}{|c|c|c|c|c|c|c|c|c|c|c|c|c|c|c|c|}
\hline & TR1 & TR2 & IR1 & IR2 & IR3 & IR4 & IR5 & IR6 & IR7 & C1 & C2 & C3 & DC1 & DC2 & DC3 \\
\hline TR1 & {$[0,0]$} & {$[0,1]$} & {$[0,0]$} & {$[0,0]$} & {$[0,0]$} & {$[4,5]$} & {$[0,0]$} & {$[0,0]$} & {$[3,4]$} & {$[0,0]$} & {$[0,0]$} & {$[0,0]$} & {$[0,0]$} & {$[3,4]$} & {$[4,5]$} \\
\hline TR2 & {$[0,0]$} & {$[0,0]$} & {$[0,1]$} & {$[0,1]$} & {$[0,0]$} & {$[0,1]$} & {$[0,0]$} & {$[1,2]$} & {$[1,2]$} & {$[0,0]$} & {$[0,0]$} & {$[0,0]$} & {$[3,4]$} & {$[4,5]$} & {$[4,5]$} \\
\hline IR1 & {$[3,4]$} & {$[1,2]$} & {$[0,0]$} & {$[0,0]$} & {$[0,0]$} & {$[0,0]$} & {$[0,0]$} & {$[0,0]$} & {$[0,1]$} & {$[0,0]$} & {$[0,0]$} & {$[0,0]$} & {$[1,2]$} & {$[2,3]$} & {$[0,0]$} \\
\hline IR2 & {$[3,4]$} & {$[0,0]$} & {$[1,2]$} & {$[0,0]$} & {$[2,3]$} & {$[0,0]$} & {$[0,0]$} & {$[0,0]$} & {$[0,0]$} & {$[0,0]$} & {$[0,0]$} & {$[0,0]$} & {$[0,1]$} & {$[0,0]$} & {$[0,0]$} \\
\hline IR3 & {$[4,5]$} & {$[3,4]$} & {$[0,0]$} & {$[0,0]$} & {$[0,0]$} & {$[0,0]$} & {$[0,0]$} & {$[2,3]$} & {$[2,3]$} & {$[3,4]$} & {$[3,4]$} & {$[1,2]$} & {$[1,2]$} & {$[2,3]$} & {$[3,4]$} \\
\hline IR4 & {$[0,0]$} & {$[0,0]$} & {$[3,4]$} & {$[0,0]$} & {$[0,0]$} & {$[0,0]$} & {$[0,0]$} & {$[0,1]$} & {$[0,1]$} & {$[0,0]$} & {$[0,0]$} & {$[0,0]$} & {$[0,0]$} & {$[0,0]$} & {$[0,0]$} \\
\hline IR5 & {$[0,0]$} & {$[0,0]$} & {$[0,0]$} & {$[0,0]$} & {$[0,0]$} & {$[0,0]$} & {$[0,0]$} & {$[0,0]$} & {$[0,0]$} & {$[0,0]$} & {$[0,0]$} & {$[0,0]$} & {$[3,4]$} & {$[3,4]$} & {$[0,0]$} \\
\hline IR6 & {$[3,4]$} & {$[2,3]$} & {$[4,5]$} & {$[0,1]$} & {$[0,0]$} & {$[0,0]$} & {$[0,0]$} & {$[0,0]$} & {$[3,4]$} & {$[1,2]$} & {$[0,0]$} & {$[2,3]$} & {$[0,0]$} & {$[0,1]$} & {$[0,1]$} \\
\hline IR7 & {$[4,5]$} & {$[0,1]$} & {$[2,3]$} & {$[0,0]$} & {$[0,0]$} & {$[0,0]$} & {$[0,0]$} & {$[0,1]$} & {$[0,0]$} & {$[0,0]$} & {$[0,0]$} & {$[0,1]$} & {$[0,0]$} & {$[3,4]$} & {$[3,4]$} \\
\hline C1 & {$[3,4]$} & {$[3,4]$} & {$[2,3]$} & {$[0,1]$} & {$[0,0]$} & {$[3,4]$} & {$[0,1]$} & {$[0,0]$} & {$[0,0]$} & {$[0,0]$} & {$[0,1]$} & {$[2,3]$} & {$[2,3]$} & {$[3,4]$} & {$[4,5]$} \\
\hline C2 & {$[1,2]$} & {$[1,2]$} & {$[2,3]$} & {$[0,0]$} & {$[0,0]$} & {$[0,0]$} & {$[0,0]$} & {$[0,0]$} & {$[0,0]$} & {$[0,0]$} & {$[0,0]$} & {$[0,0]$} & {$[0,0]$} & {$[1,2]$} & {$[2,3]$} \\
\hline C3 & {$[3,4]$} & {$[3,4]$} & {$[3,4]$} & {$[0,1]$} & {$[0,0]$} & {$[0,0]$} & {$[0,0]$} & {$[0,1]$} & {$[0,1]$} & {$[4,5]$} & {$[1,2]$} & {$[0,0]$} & {$[4,5]$} & {$[3,4]$} & {$[4,5]$} \\
\hline DC1 & {$[4,5]$} & {$[0,0]$} & {$[3,4]$} & {$[0,0]$} & {$[0,0]$} & {$[0,0]$} & {$[0,0]$} & {$[0,0]$} & {$[0,0]$} & {$[0,0]$} & {$[0,0]$} & {$[0,0]$} & {$[0,0]$} & {$[0,1]$} & {$[0,1]$} \\
\hline DC2 & {$[3,4]$} & {$[0,1]$} & {$[0,1]$} & {$[0,0]$} & {$[0,0]$} & {$[0,0]$} & {$[0,1]$} & {$[0,0]$} & {$[0,0]$} & {$[1,2]$} & {$[0,1]$} & {$[1,2]$} & {$[2,3]$} & {$[0,0]$} & {$[2,3]$} \\
\hline DC3 & {$[0,1]$} & {$[4,5]$} & {$[3,4]$} & {$[0,1]$} & {$[0,0]$} & {$[0,0]$} & {$[0,0]$} & {$[0,0]$} & {$[0,0]$} & {$[3,4]$} & {$[0,1]$} & {$[3,4]$} & {$[3,4]$} & {$[4,5]$} & {$[0,0]$} \\
\hline
\end{tabular}

Table 9: The direct-relation matrix for barriers for implementing Industry 4.0 by Expert 6 .

\begin{tabular}{|c|c|c|c|c|c|c|l|l|l|l|l|l|l|l|l|}
\hline & TR1 & TR2 & IR1 & IR2 & IR3 & IR4 & IR5 & IR6 & IR7 & C1 & C2 & C3 & DC1 & DC2 & DC3 \\
\hline TR1 & {$[0,0]$} & {$[1,2]$} & {$[0,0]$} & {$[0,1]$} & {$[0,0]$} & {$[3,4]$} & {$[0,0]$} & {$[0,0]$} & {$[2,3]$} & {$[0,0]$} & {$[0,1]$} & {$[0,0]$} & {$[0,0]$} & {$[4,5]$} & {$[4,5]$} \\
\hline TR2 & {$[0,0]$} & {$[0,0]$} & {$[1,2]$} & {$[0,1]$} & {$[0,0]$} & {$[0,0]$} & {$[0,0]$} & {$[1,2]$} & {$[1,2]$} & {$[0,0]$} & {$[0,1]$} & {$[0,0]$} & {$[2,3]$} & {$[4,5]$} & {$[4,5]$} \\
\hline IR1 & {$[3,4]$} & {$[0,1]$} & {$[0,0]$} & {$[0,0]$} & {$[0,1]$} & {$[0,0]$} & {$[0,0]$} & {$[0,0]$} & {$[2,3]$} & {$[0,0]$} & {$[0,0]$} & {$[0,0]$} & {$[1,2]$} & {$[2,3]$} & {$[1,2]$} \\
\hline IR2 & {$[4,5]$} & {$[0,0]$} & {$[1,2]$} & {$[0,0]$} & {$[1,2]$} & {$[0,0]$} & {$[0,0]$} & {$[0,0]$} & {$[0,0]$} & {$[0,0]$} & {$[0,0]$} & {$[0,0]$} & {$[0,1]$} & {$[0,0]$} & {$[0,0]$} \\
\hline IR3 & {$[3,4]$} & {$[3,4]$} & {$[0,0]$} & {$[0,0]$} & {$[0,0]$} & {$[0,1]$} & {$[0,0]$} & {$[2,3]$} & {$[2,3]$} & {$[3,4]$} & {$[2,3]$} & {$[2,3]$} & {$[1,2]$} & {$[2,3]$} & {$[3,4]$} \\
\hline IR4 & {$[0,0]$} & {$[0,0]$} & {$[4,5]$} & {$[0,0]$} & {$[0,0]$} & {$[0,0]$} & {$[0,0]$} & {$[0,0]$} & {$[0,1]$} & {$[0,0]$} & {$[0,0]$} & {$[0,0]$} & {$[0,0]$} & {$[0,0]$} & {$[0,0]$} \\
\hline IR5 & {$[0,0]$} & {$[0,0]$} & {$[0,0]$} & {$[0,0]$} & {$[0,0]$} & {$[0,0]$} & {$[0,0]$} & {$[0,0]$} & {$[0,0]$} & {$[0,0]$} & {$[0,0]$} & {$[0,1]$} & {$[4,5]$} & {$[2,3]$} & {$[0,0]$} \\
\hline IR6 & {$[3,4]$} & {$[2,3]$} & {$[4,5]$} & {$[0,1]$} & {$[0,0]$} & {$[0,0]$} & {$[0,0]$} & {$[0,0]$} & {$[3,4]$} & {$[1,2]$} & {$[0,0]$} & {$[2,3]$} & {$[0,0]$} & {$[0,1]$} & {$[0,1]$} \\
\hline IR7 & {$[3,4]$} & {$[0,1]$} & {$[2,3]$} & {$[0,0]$} & {$[0,0]$} & {$[0,1]$} & {$[0,0]$} & {$[0,1]$} & {$[0,0]$} & {$[0,0]$} & {$[0,0]$} & {$[0,1]$} & {$[0,0]$} & {$[3,4]$} & {$[3,4]$} \\
\hline C1 & {$[3,4]$} & {$[3,4]$} & {$[2,3]$} & {$[0,1]$} & {$[0,0]$} & {$[3,4]$} & {$[0,1]$} & {$[0,0]$} & {$[0,0]$} & {$[0,0]$} & {$[0,1]$} & {$[2,3]$} & {$[2,3]$} & {$[3,4]$} & {$[4,5]$} \\
\hline C2 & {$[2,3]$} & {$[2,3]$} & {$[2,3]$} & {$[0,0]$} & {$[0,0]$} & {$[0,0]$} & {$[0,0]$} & {$[0,0]$} & {$[0,1]$} & {$[0,0]$} & {$[0,0]$} & {$[0,0]$} & {$[0,0]$} & {$[0,0]$} & {$[1,2]$} \\
\hline C3 & {$[3,4]$} & {$[2,3]$} & {$[2,3]$} & {$[0,1]$} & {$[0,0]$} & {$[0,0]$} & {$[0,1]$} & {$[1,2]$} & {$[0,1]$} & {$[4,5]$} & {$[1,2]$} & {$[0,0]$} & {$[4,5]$} & {$[3,4]$} & {$[4,5]$} \\
\hline DC1 & {$[3,4]$} & {$[0,0]$} & {$[2,3]$} & {$[0,0]$} & {$[0,0]$} & {$[0,0]$} & {$[1,2]$} & {$[0,0]$} & {$[0,1]$} & {$[0,0]$} & {$[0,0]$} & {$[0,0]$} & {$[0,0]$} & {$[1,2]$} & {$[0,0]$} \\
\hline DC2 & {$[3,4]$} & {$[0,1]$} & {$[0,1]$} & {$[0,0]$} & {$[0,0]$} & {$[0,0]$} & {$[0,1]$} & {$[0,0]$} & {$[0,0]$} & {$[1,2]$} & {$[0,1]$} & {$[1,2]$} & {$[2,3]$} & {$[0,0]$} & {$[2,3]$} \\
\hline DC3 & {$[1,2]$} & {$[4,5]$} & {$[3,4]$} & {$[0,0]$} & {$[0,0]$} & {$[0,0]$} & {$[0,0]$} & {$[0,0]$} & {$[0,0]$} & {$[3,4]$} & {$[0,1]$} & {$[3,4]$} & {$[3,4]$} & {$[4,5]$} & {$[0,0]$} \\
\hline
\end{tabular}

